\title{
ESTRATIGRAFIA DEL SECTOR 5-F DE LA ALCUDIA DE ELCHE
}

\author{
RAFAEL RAMOS FERNANDEZ \\ Museo Arqueológico de Elche
}

\begin{abstract}
Las últimas campañas de excavación en La Alcudia de Elche (Alicante) han proporcionado una interesante estratigrafía desde la época preibérica hasta la visigótica, que confirma los estudios ya realizados con anterioridad.

The last works at the La Alcudia (Elche, Alicante) have discovered a very interesting stratigraphical sequence, from the Preiberic to the Visigothic Periods. That confirmates previous studies about the history of the ancient Illici.
\end{abstract}

Como avance de la información general de las tareas realizadas en el sector 5-F de este yacimiento pasamos a exponer sucintamente las precisiones alli obtenidas.

Para la realización de los trabajos hemos empleado una cuadrícula progresiva de cinco metros de patrón que se ha aplicado ya a diecinueve sondeos, divisibles en setenta y seis casillas, que estratigráficamente responden a una superposición integrada por un nivel agrícola de base ondulada que ofrece suaves buzamientos y cuyo espesor oscila entre 22 centímetros y 38 centímetros, bajo el cual se desarrollan ocho estratos con una potencia global de 4,82 metros, por lo que los cortes efectuados alcanzan los cinco metros de profundidad en los sondeos que no han ofrecido estructuras sólidas de época romana, por lo cual sin su destrucción ha sido posible llevar a cabo esta excavación hasta la tierra virgen (Lám. I y figs. 1, 2, 3 y 4).

El estudio general de las campañas de excavación realizadas (1) hasta ahora en el sector 5-F (fig. 5) ha mostrado la existencia de pobres construcciones de época visigoda asociadas al primer estrato del yacimiento, estrato A, que ofrece su nivel de pavimentos a 55 centímetros de la superficie del terreno y una potencia media de 23 centímetros integrada por sus niveles de escombros y de restos que, en algunas ocasiones, forman parte del nivel agrícola como alteración de este estrato $\mathrm{A}$, a consecuencia de las tareas de desmonte efectuadas a principios de nuestro siglo para conversión de estas zonas en tierras de regadío.

En estos sondeos el estrato de época visigoda ofreció restos de arranque de muros de canto rodado y piedra mediana y pequeña, con fecuentes fragmentos de ladrillos y tejas intercalados procedentes de construcciones de época romana que son así reutilizados, que configuran lugares de habitación de planta rectangular y una gran dependencia absidada, con pavimentos de lechada de cal sobre tierra apisonada y de tierra batida en-

(1) A. RAMOS-R. RAMOS. «Excavaciones en La Alcudia. Memoria de las excavaciones practicadas durante 1977-78 y 79. Campañas 43-44-45». Subdirección General de Arqueología. «Informe de las $46 .{ }^{a}$ y

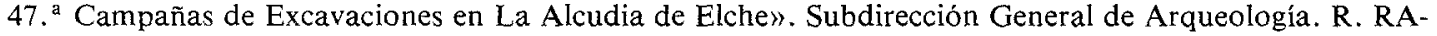
MOS. «Excavaciones en La Alcudia. Illici romana». Historia 16, n. ${ }^{\circ}$ 68. Madrid, 1981; "Actividades del Museo Monográfico de La Alcudia». Festa d'Elig. Elche, 1982; «La Alcudia de Elche». Revista de Arqueología, $n .^{\circ} 24$. Madrid, 1983. 
durecida, de 4 a 8 centímetros de grosor, y con unos conjuntos de materiales cerámicos caracterizados por cuencos, cazuelas, escudillas, ollas y otros recipientes de cocina de paredes rectas y base plana modelados a mano, de superficies exteriores lavadas, palmeadas o espatuladas, de pastas grises, rojas, marrones o negras, con abundantes desengrasantes micáceos y de paredes ennegrecidas al exterior; por recipientes de tipo botella con asas, torneados, de pastas amarillentas terrosas; por fragmentos de vasijas con decoración de cintas aplicadas y con motivos incisos de buril romo; y por recipientes de pasta amarillenta, de superficie exterior decorada en crudo con bandas de arañado.

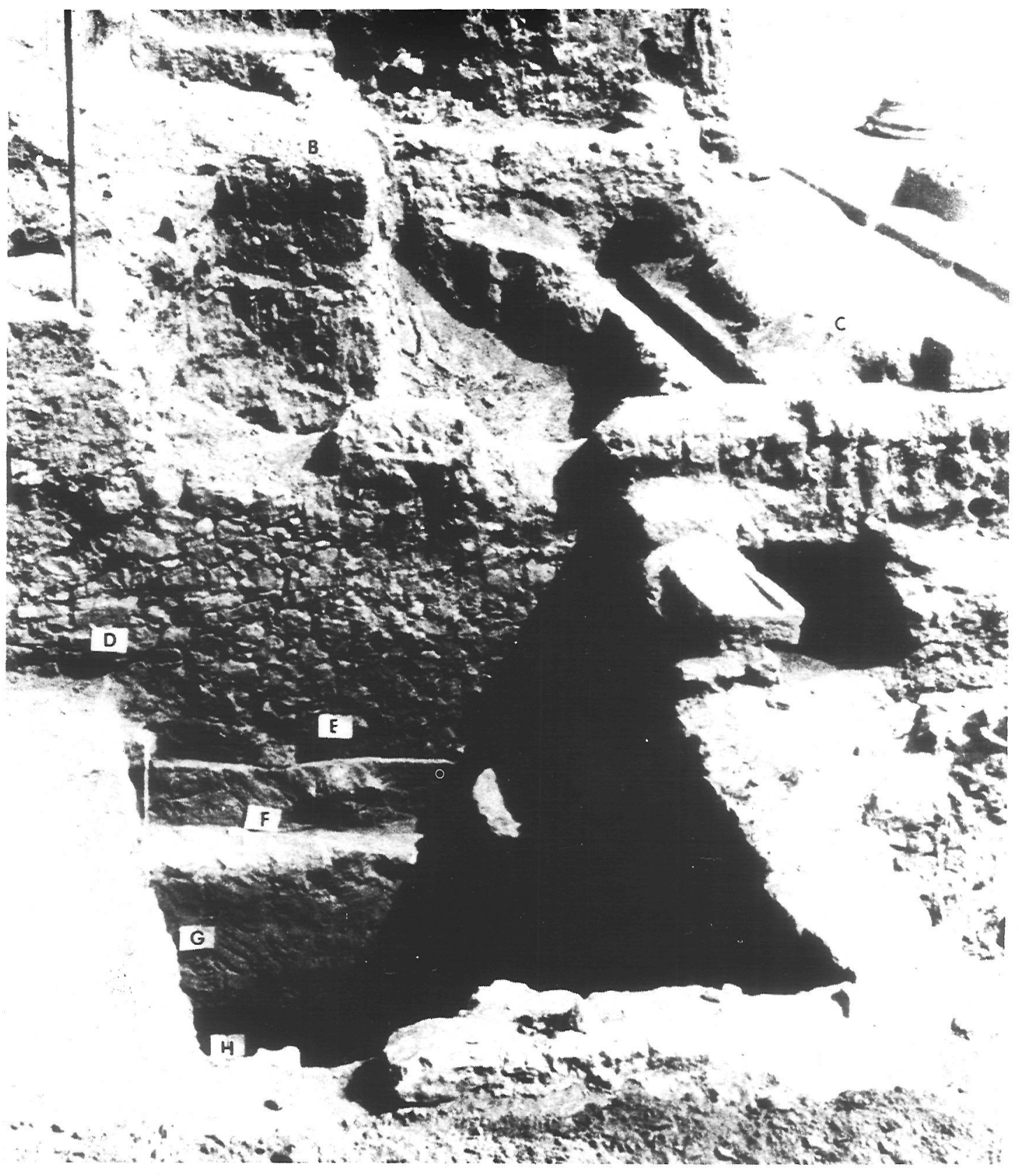

Lám. I. Estratigrafía 


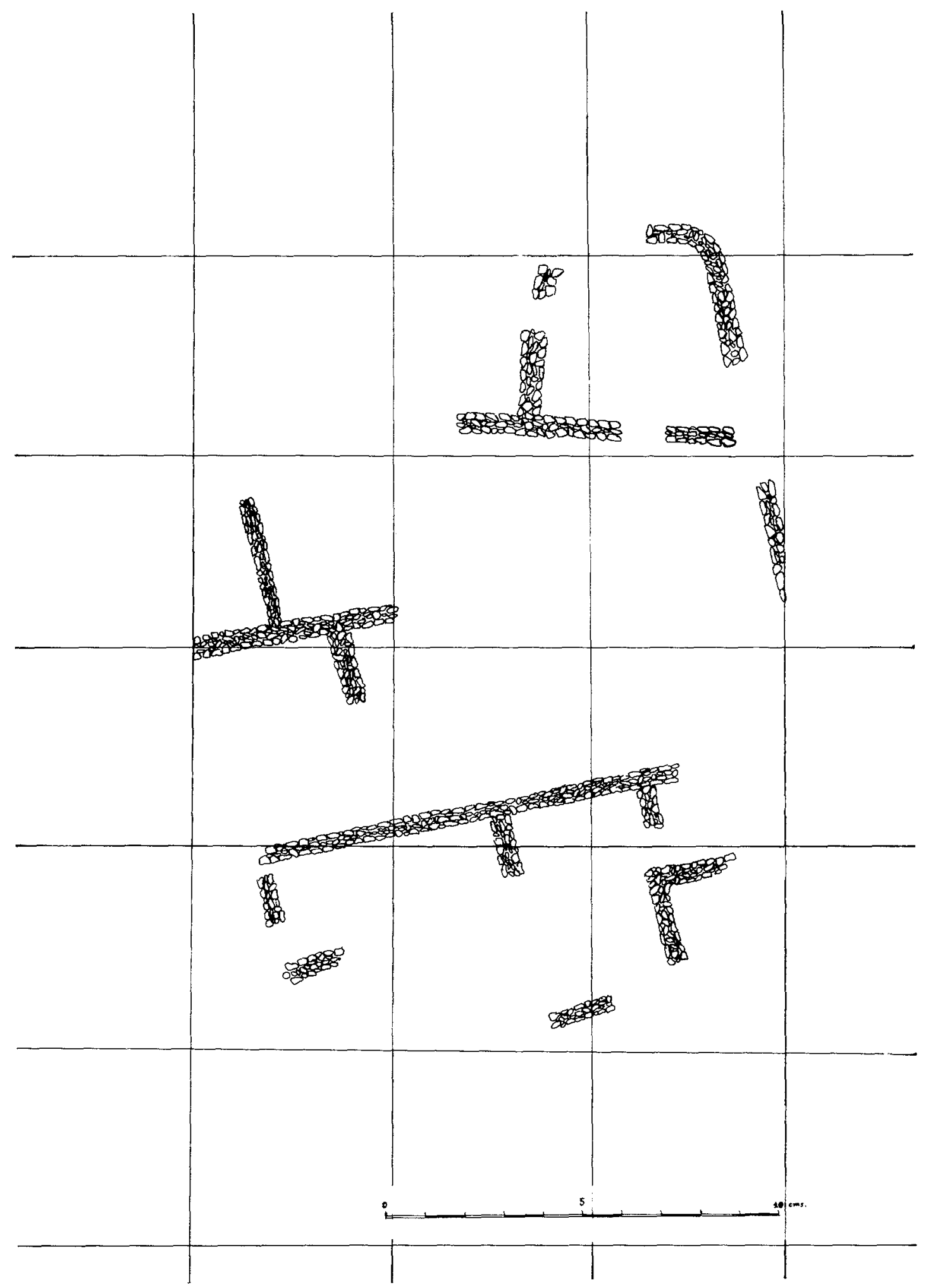

Fig. 1. Nivel visigodo 


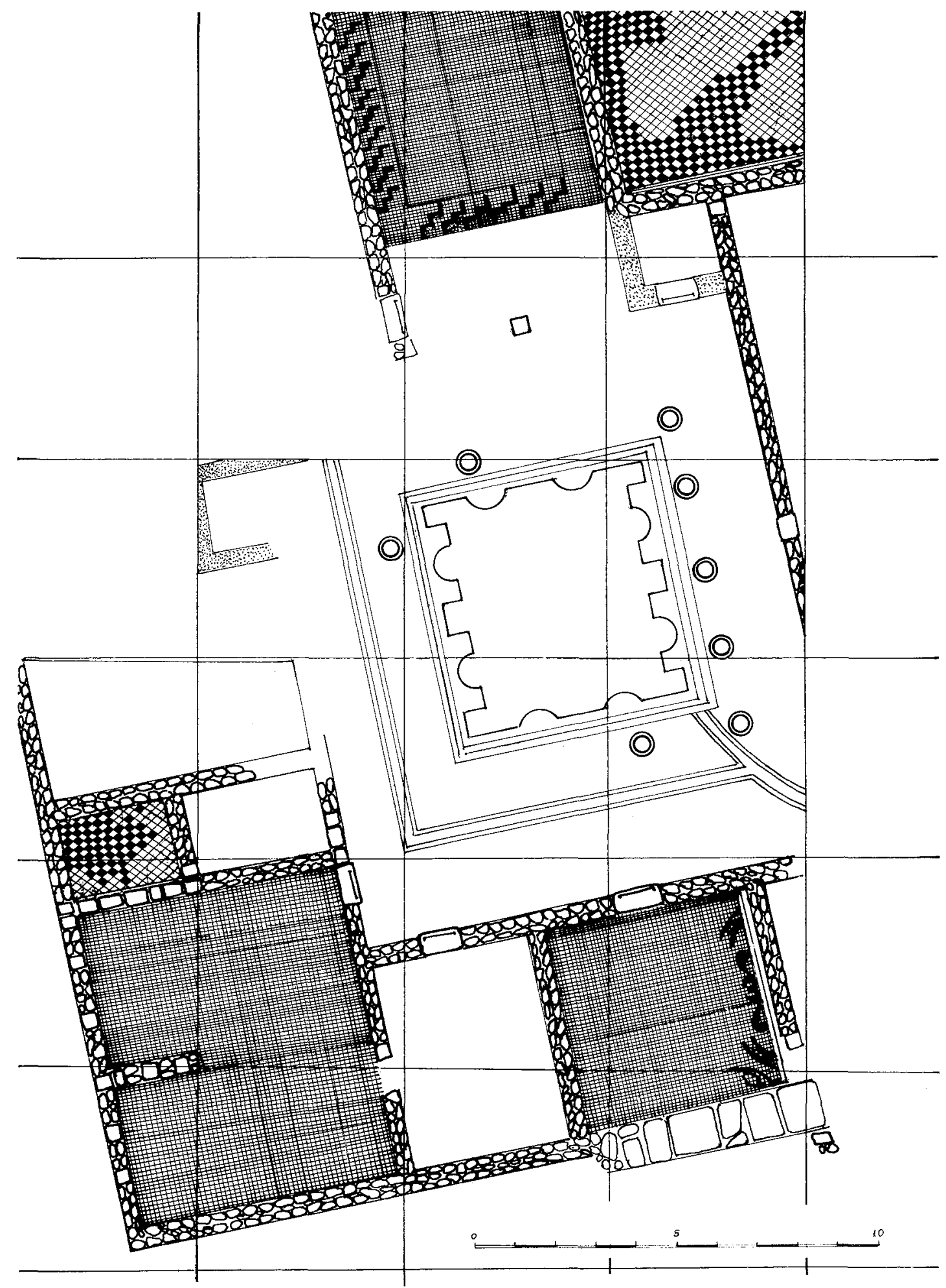

Fig. 2. Nivel romano 


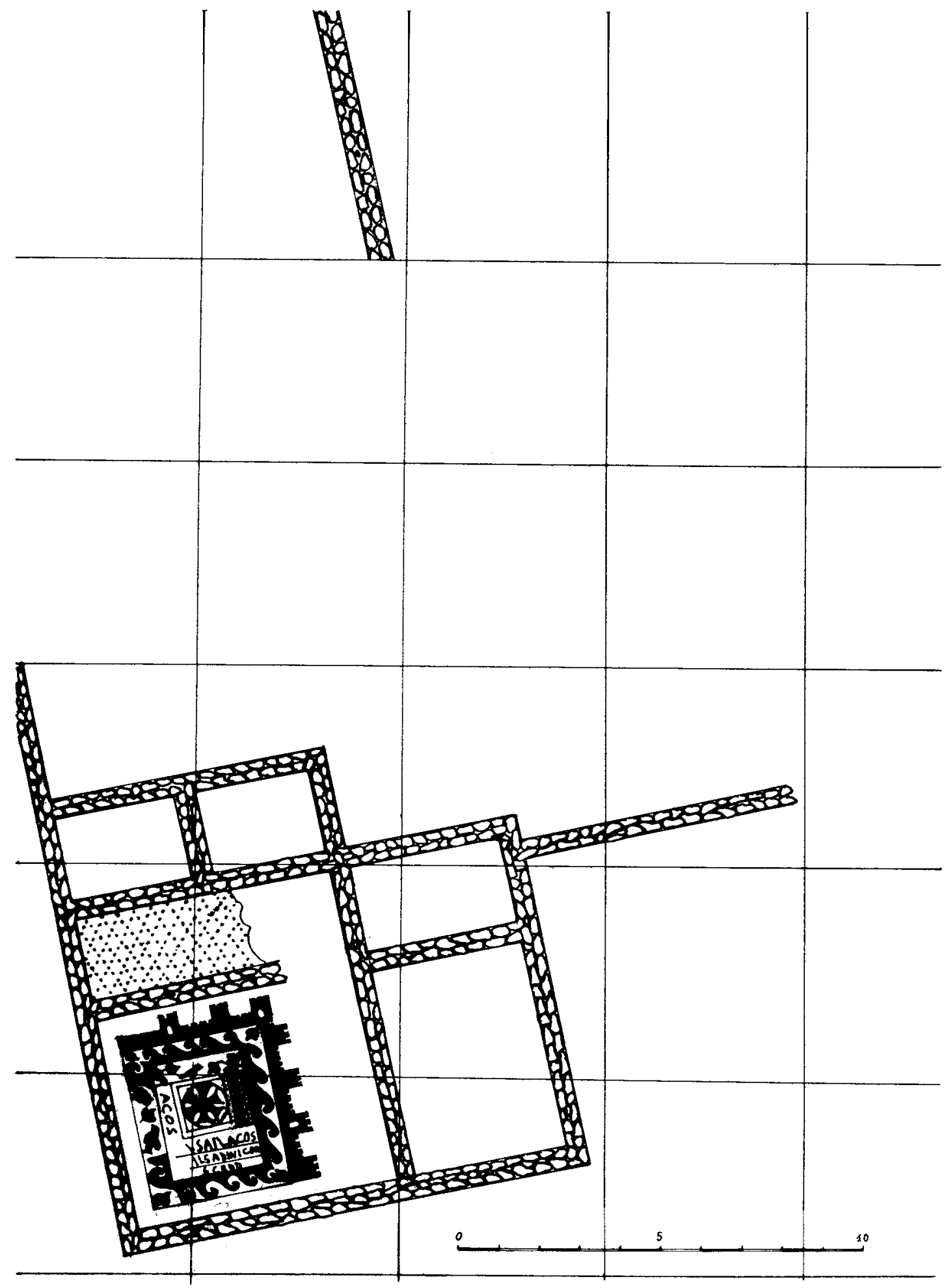

Fig. 3. Nivel ibero-romano 


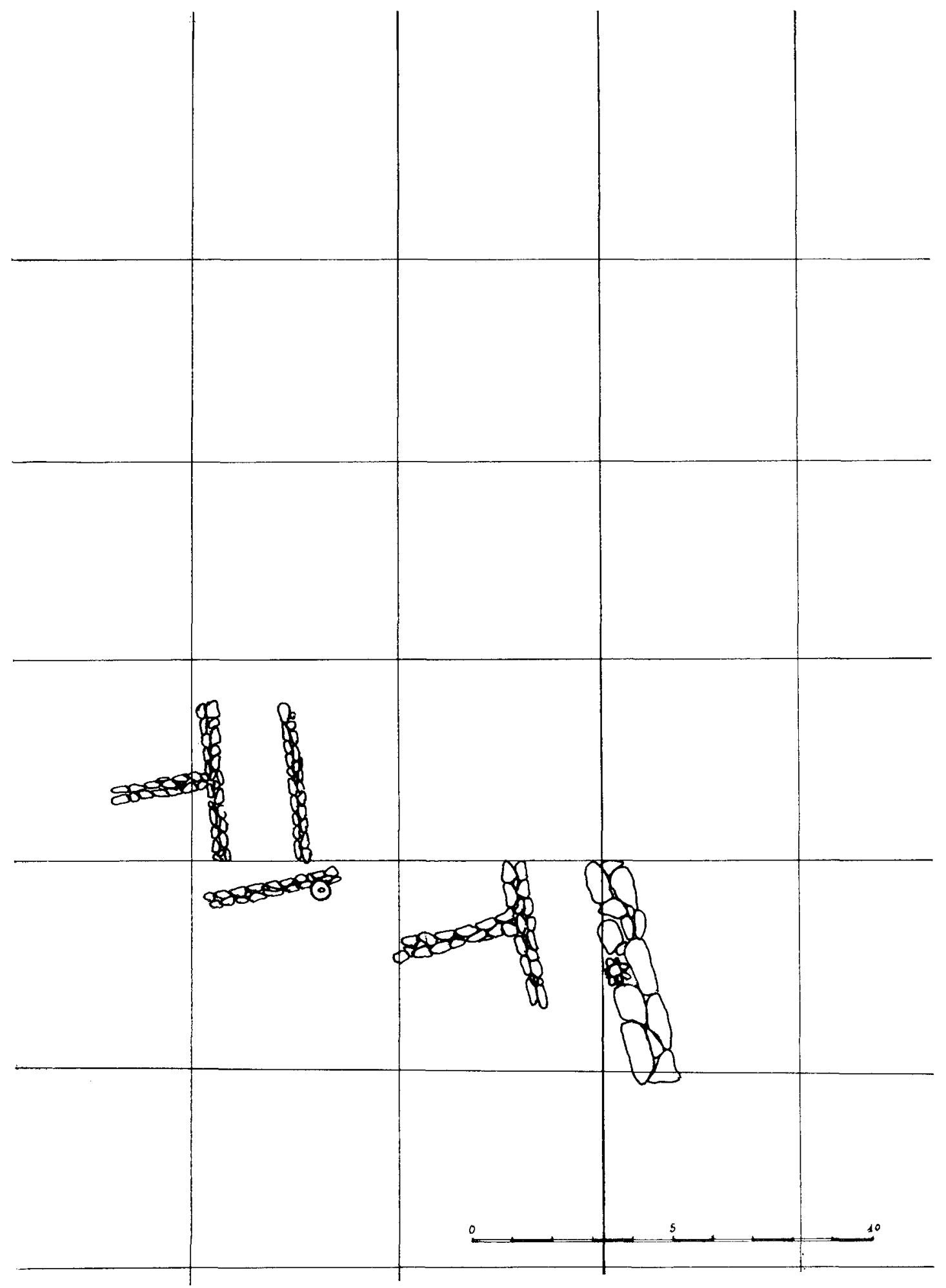

Fig. 4. Nivel ibérico 


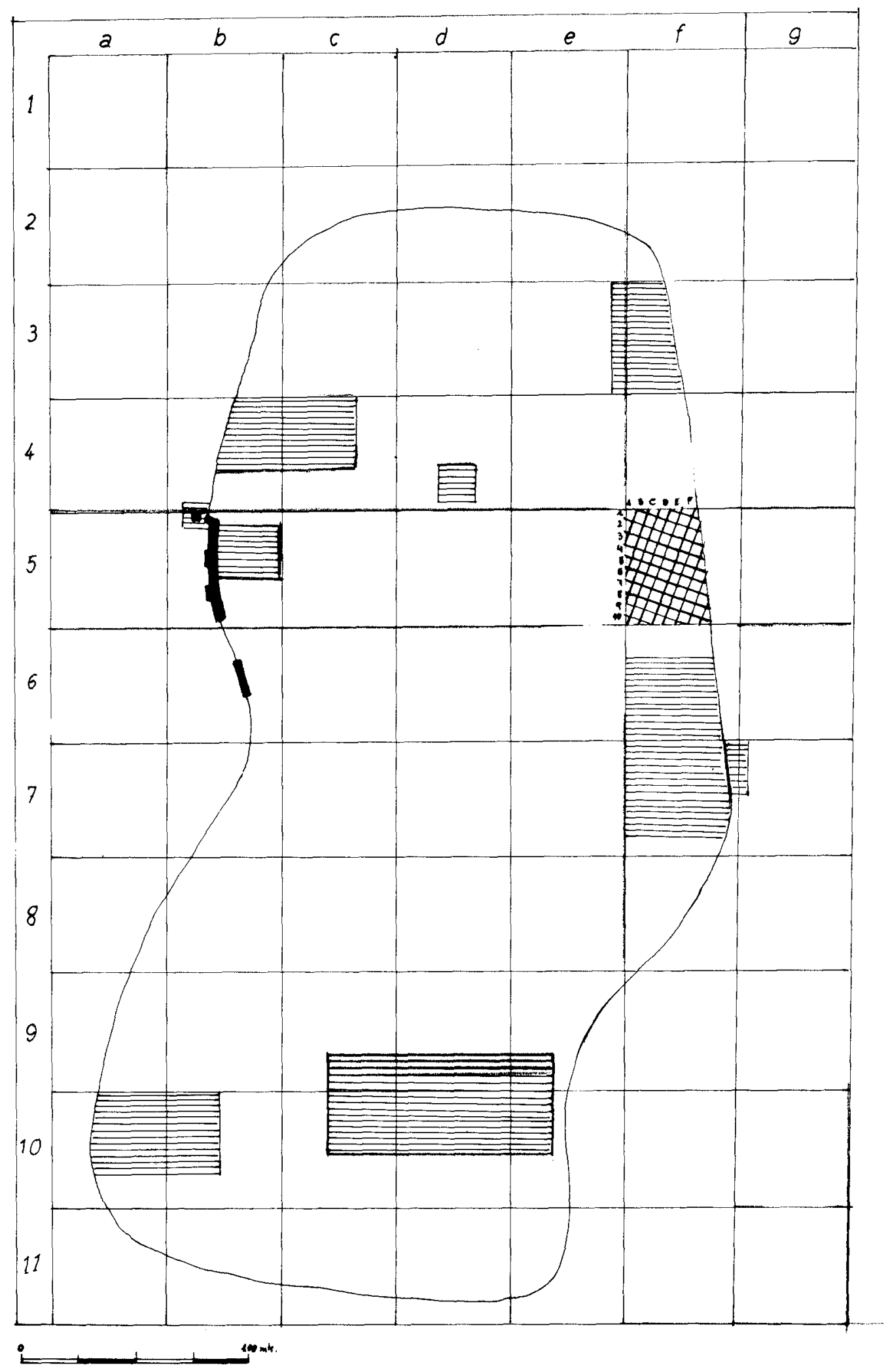

Fig. 5. Planimetría del yacimiento con indicación de los sectores excavados. 
En el conjunto de materiales hallado en este estrato ha sido especialmente significativa la presencia de un cuenco globular incompleto de 16 centímetros de diámetro de boca, de pasta marrón rojiza, fruto de su cocción a fuego oxidante, y de núcleo negro, modelada a mano, con abundante desengrasante micáceo y de superficie exterior lavada y ennegrecida (fig. A-1); una cazuela incompleta de pasta negra con superficies marrones, cocida a fuego oxidante, modelada a mano, con desengrasante micáceo, de 24 centímetros de diámetro de boca (fig. A-2); un fragmento de recipiente tipo botella con asa, de pasta amarillenta y superficie poco cuidada (fig. A-3); varios fragmentos de una vasija de pasta amarillenta, de superficie exterior decorada por bandas de arañado en crudo (fig. A-4); un cuenco incompleto de pasta negra, de superficie exterior espatulada (fig. A-5.1); varios fragmentos de un cuenco de pasta negra, de superficie exterior espatulada, con asa aplicada horizontal (fig. A-5.2); una escudilla incompleta de barro marrón ennegrecido al exterior y de base plana (fig. A-5.3); una vasija de cocina de paredes rectas, base plana y asa aplicada horizontal, de pasta marrón con abundante desengrasante micáceo, superficie exterior ennegrecida y una línea ondulante incisa como elemento de decoración. Mide 22 centímetros de diámetro de boca y 15 centímetros de altura (fig. A-6); un vaso incompleto de paredes rectas y base plana, de barro rojo con abundante desengrasante micáceo y superficies ennegrecidas (fig. A-7); un fragmento de cuello y labio de una vasija de barro rojizo con decoración incisa de buril romo (fig. A-8.1); un fragmento de una vasija de barro amarillento claro y estructura terrosa (fig. A-8.2); varios fragmentos de la boca de una vasija de pasta amarillenta decorada con incisiones e impresiones realizadas con buril o punzón romo (fig. A-9.1); un fragmento de la boca de una vasija de barro rojizo con reborde o cinta plegada bajo el labio (fig. A-9.2); y varios fragmentos de ladrillo decorado, hallados formando parte de los restos de muros de esta época visigoda, empleados como material de construcción, que consiguientemente deben asociarse en cuanto a su fabricación al estrato y período anterior a éste en que aparecen (fig. A-10, B).

Levantados los pavimentos del estrato A se penetró en la potencia del estrato $\mathrm{B}$, correspondiente a la época del Bajo Imperio, de 24 centímetros, cuyo nivel de pavimentos, a 83 centímetros de la superficie del terreno, está constituido, en las distintas dependencias, por pisos de argamasa de cal y cantos rodados, de adobes, de arcilla pisada sobre cantos y de pequeñas piedras cogidas con barro. Sus estructuras responden a un predominio de los muros de adobe estucados con pinturas de los llamados tipos decadentes, aunque también aparecen muros de piedra ensamblada de tamaño mediano, montados directamente sobre su nivel de pavimentos. Si bien en buena parte del sector se han reutilizado estructuras del estrato inferior a éste que nos ocupa. En tales sondeos bajo las construcciones de época visigoda se ofrece un potente estrato romano que contiene una vivienda que fue habitada en dos fases: la de su construcción, posiblemente a fines del siglo I de J. C., que se sostuvo hasta el año 256; y la de su reutilización tras la destrucción causada en la ciudad por las incursiones francas que, con leves modificaciones perduró hasta el momento de los cambios que se produjeron en Illici a mediados del siglo $\mathrm{V}$ de J.C.

El conjunto de materiales de este estrato B está caracterizado por la presencia de cerámica estampada gris y roja, de gris ahumada, de sigillatas claras de bordes ennegrecidos, de olpes con decoración pintada, lucernas cristianas, vasijas de pasta amarillenta y ánforas, asociadas a piezas monetales del Bajo Imperio.

En la excavación de este sector ha sido significativo el hallażgo de una matriz de piedra caliza grabada con círculos concéntricos para el estampillado de cerámica, que posiblemente implique la existencia de producciones locales de este tipo cerámico (fig. B-1.1); una jarra incompleta de barro amarillento con desengrasante micáceo (fig. B-1.2); un fragmento de fuente, de 25 centímetros de diámetro, de estampada gris con decoración de rosetas en su labio (fig. B-2.1); un fragmento de estampada gris de una fuente de 33 centímetros de diámetro (fig. B-2.2); un fragmento de plato de estampada 


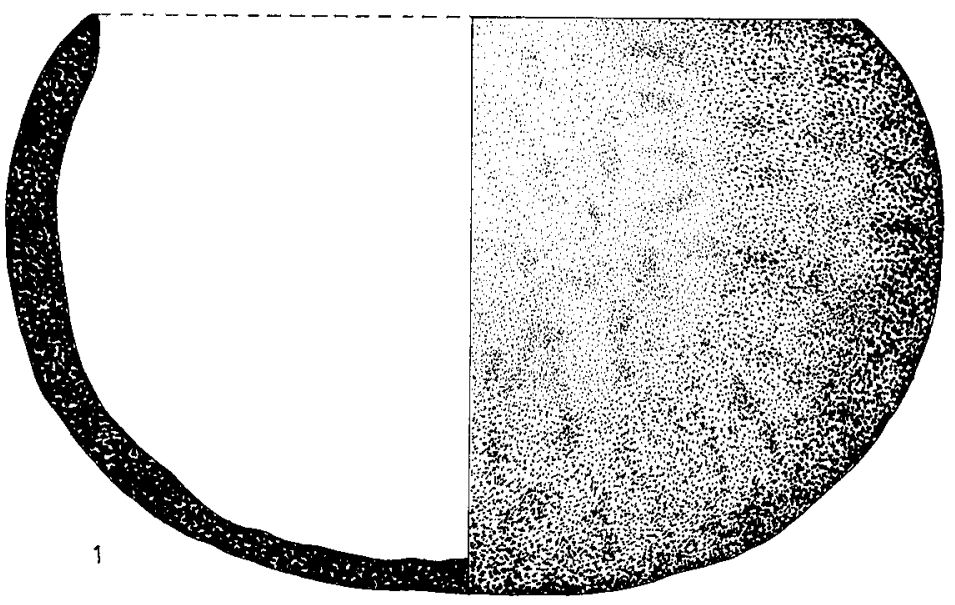

A
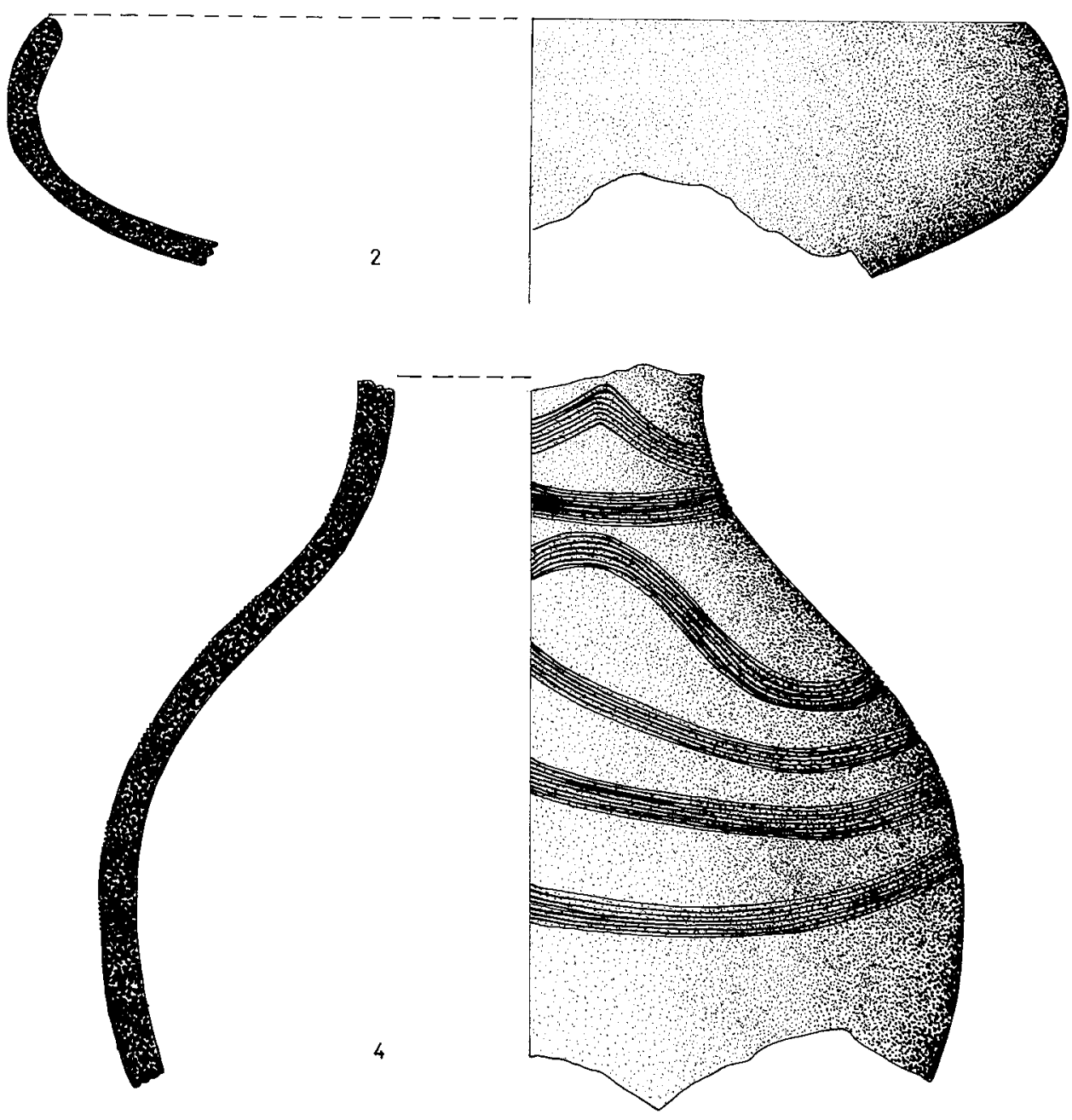

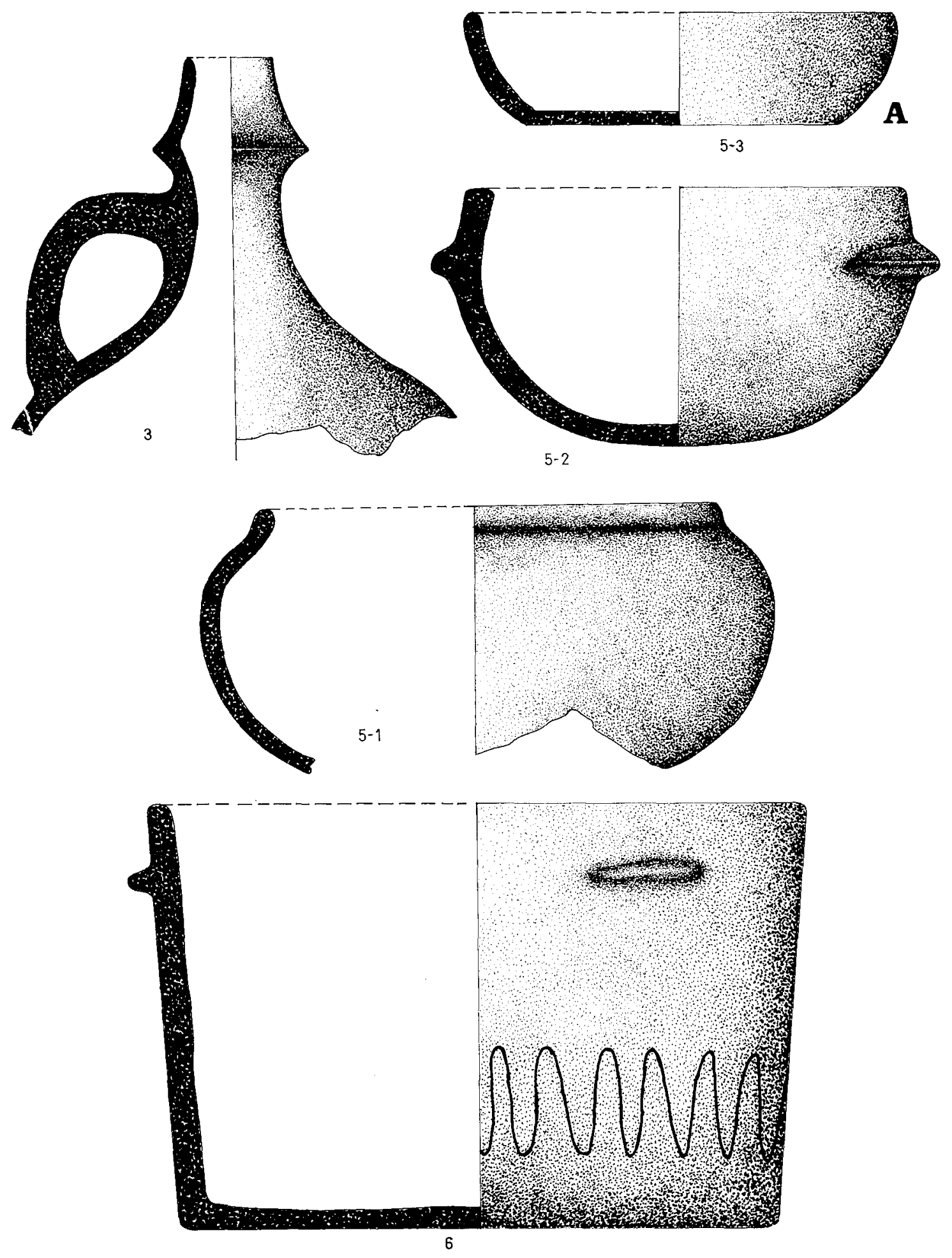

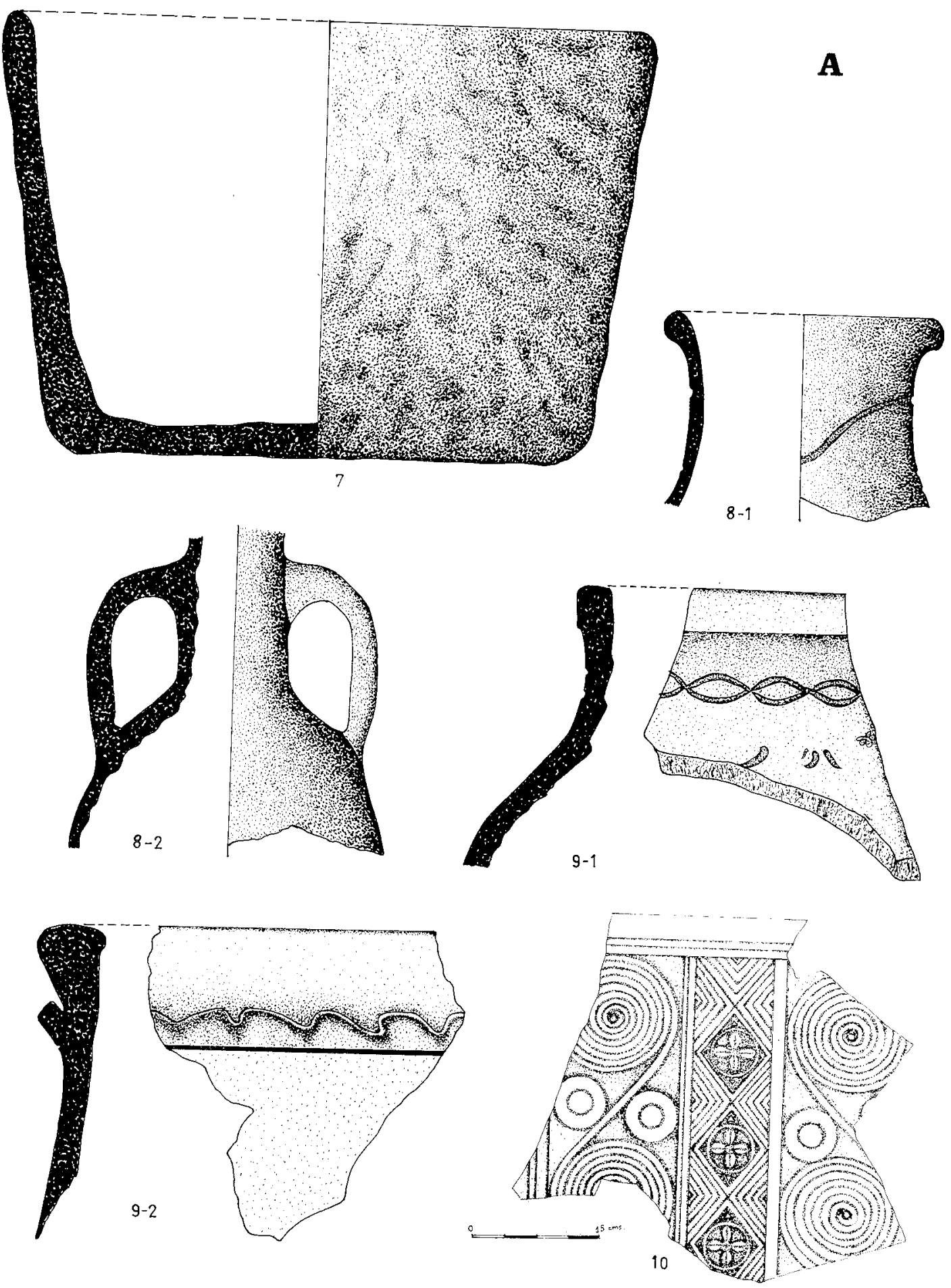

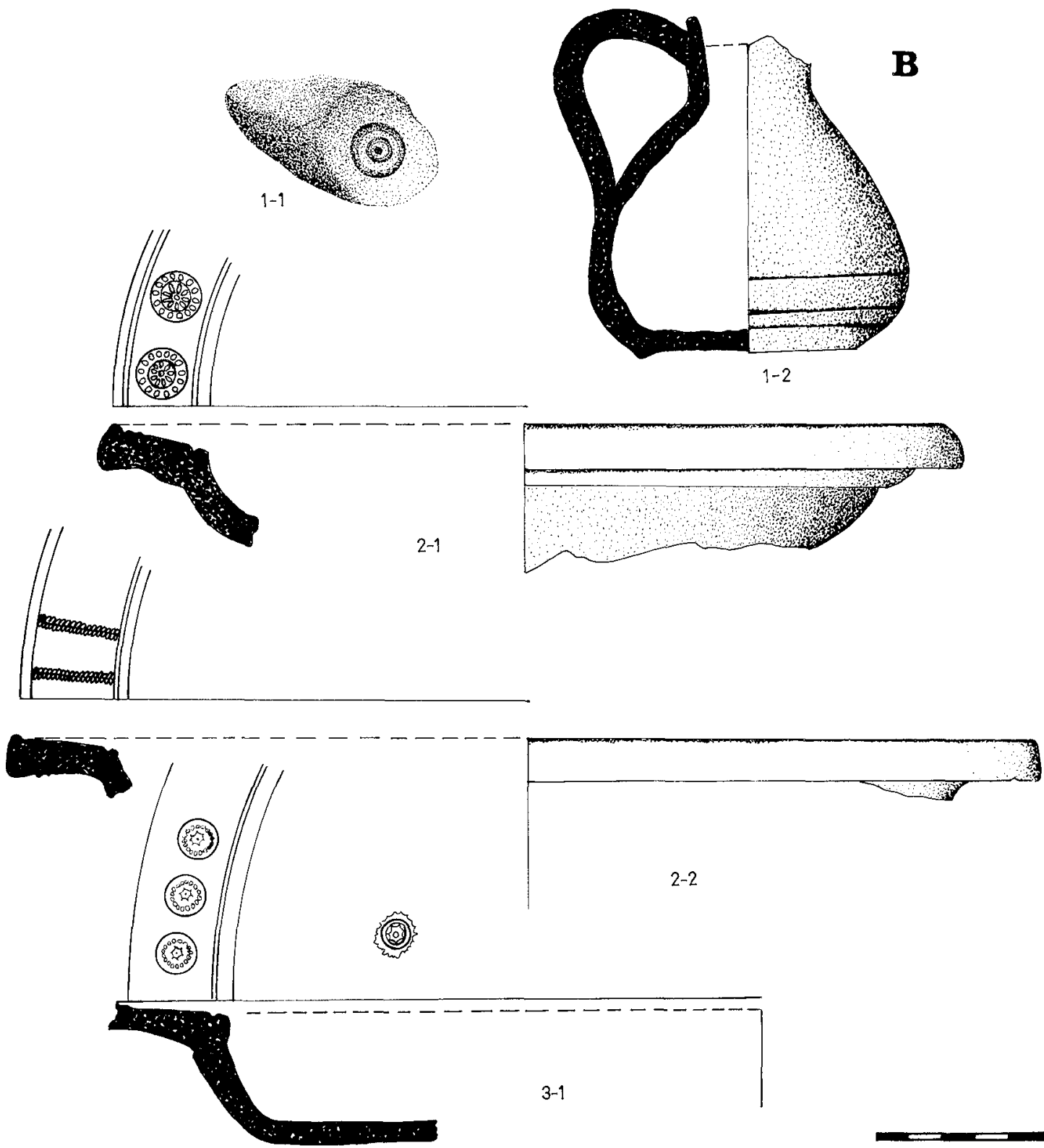

$2-2$

gris de 38 centímetros de diámetro (fig. B-3.1); un fragmento de base de plato de estampada roja (fig. B-3.2); un fragmento de labio de cerámica estampada gris (fig. B-3.3); varios fragmentos de un olpe con decoración pintada de tradición ibérica (fig. B-4.1); un fragmento de base de plato de estampada roja (fig. B-4.2); una vasija incompleta de cerámica estampada gris, de pasta gris verdosa y engobe gris plomizo, variante de la forma G.18 de Rigoir (fig. B-5); varios fragmentos de un plato de sigillata clara D, forma 51 A de Lamboglia (fig. B-6.1); varios fragmentos de un plato de sigillata clara D, forma 42 de Lamboglia (fig. B-6.2); un fragmento de plato de sigillata clara B (fig. B-7.1); una vasija incompleta de sigillata clara, F.40 de Hayes (fig. B-7.2); y además ha sido muy interesante el hecho de que, cuando se procedía a la limpieza del pavimento de adobes en una habitación de esta vivienda, se apreció una alteración del mismo en forma 

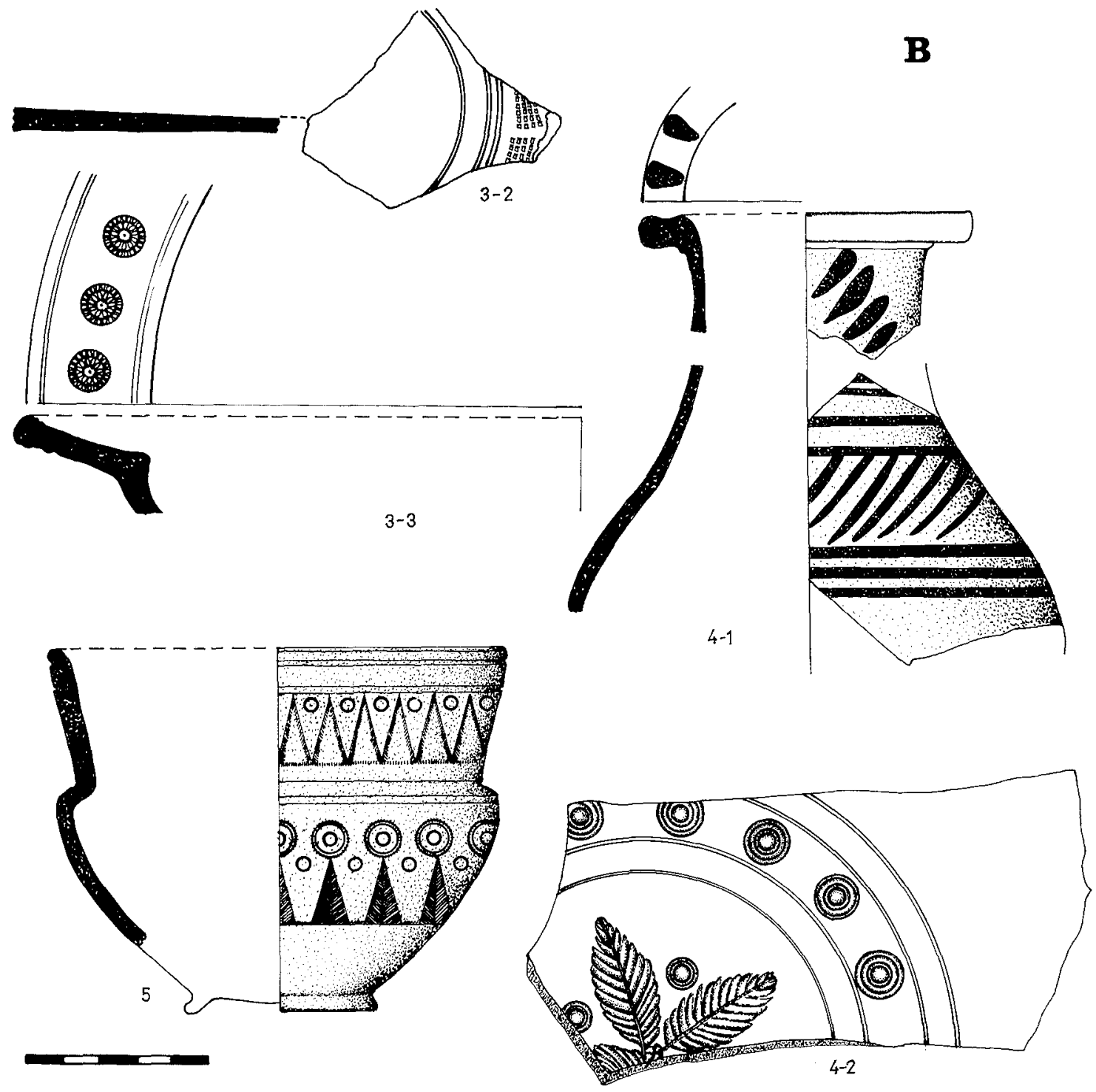

circular, delatada por coloración, puesto que la tonalidad más oscura de lo normal en este punto del pavimento debía responder a una mayor absorción de humedad, por lo que se inició el levantamiento de los adobes del pavimento en este lugar y se observó debajo de ellos, en un hoyo globular relleno de tierra, la existencia de una vasija de cocina y se procedió a vaciar el centro indicado. De esta forma se comprobó que se trataba de una pequeña cavidad excavada bajo pavimento y previa extracción de los adobes que tras el relleno del depósito fueron de nuevo colocados. En este hoyo, indudable escondrijo intencionado, se descubrió la ya indicada olla (fig. B-8) que contenía dos lucernas cristianas, una decorada en su disco con un motivo bíblico: Abraham dispuesto al sacrificio de Isaac (fig. B-9); y la otra que ofrece como tema decorativo una paloma (fig. B-10). La condición de escondrijo de este hallazgo y el carácter de su contenido, no de valor monetal sino simbólico, las dos lucernas cristianas, plantean una importante problemática histórica que deberá ser ampliamente valorada.

También, en el conjunto de materiales de este estrato, han aparecido pequeños y medianos bronces de Maximino II, Valentiniano y Constantino. 


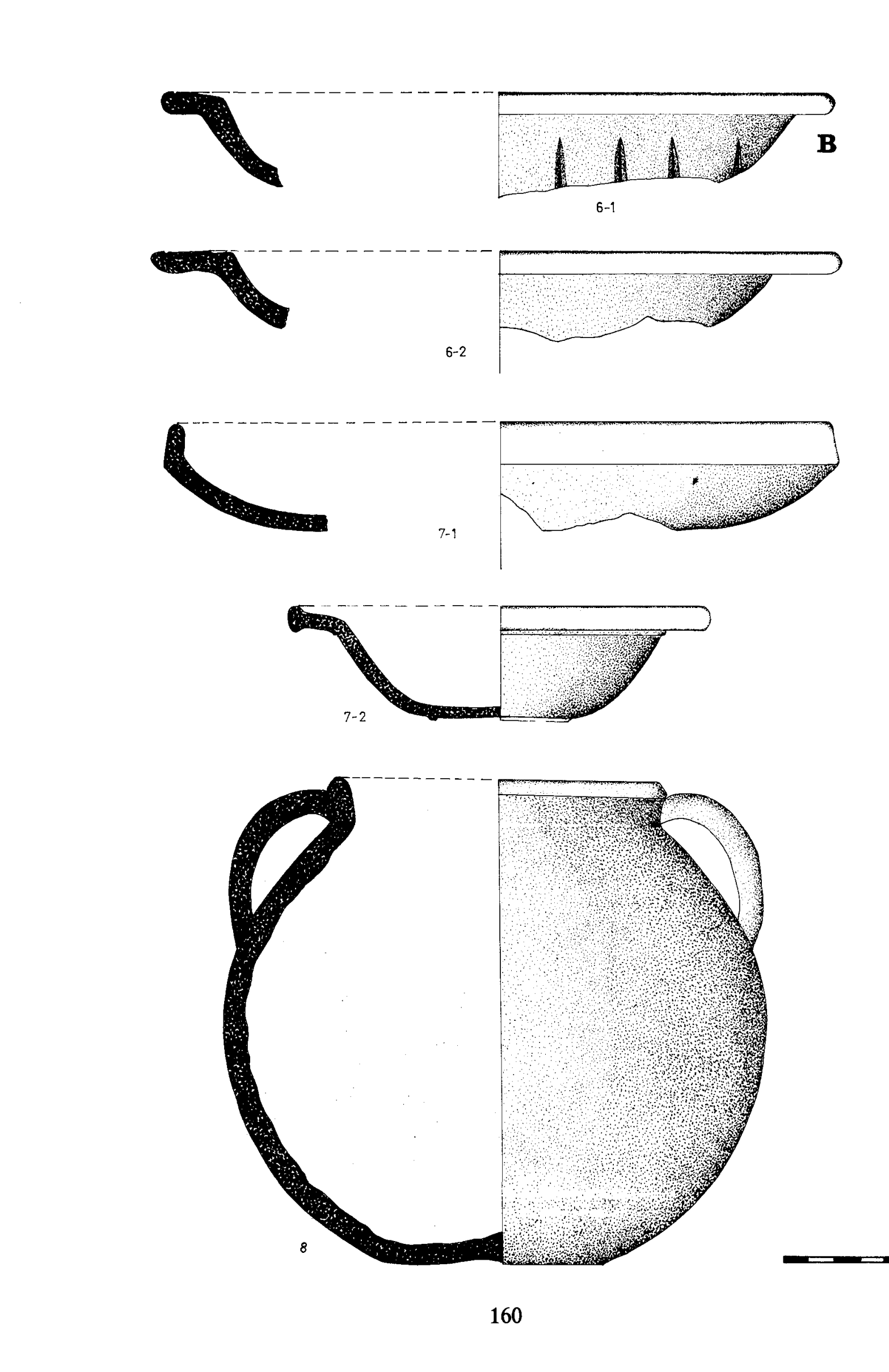



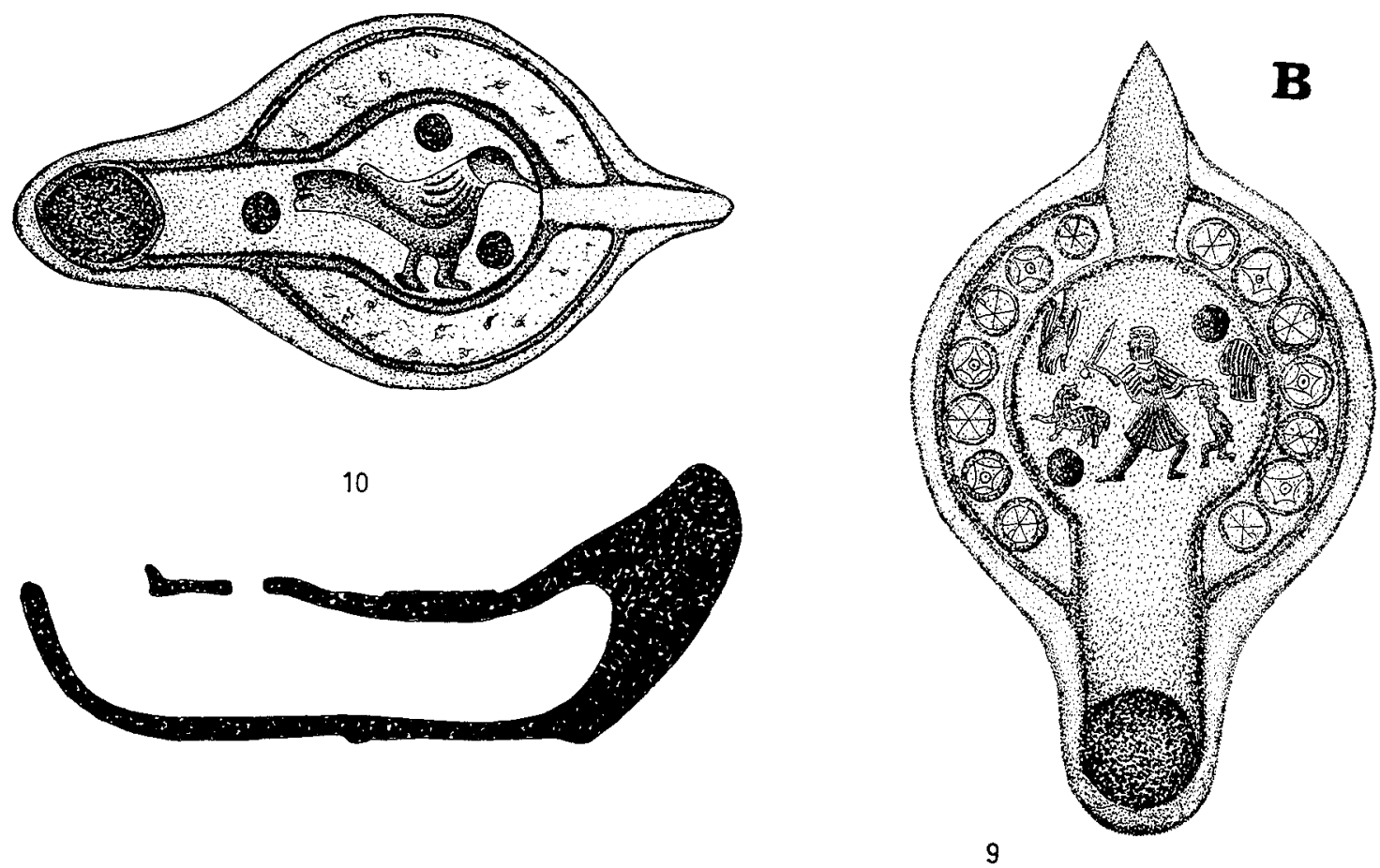

9

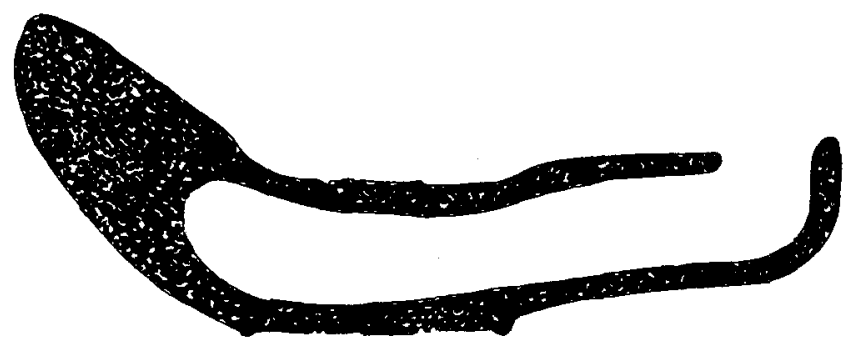

La excavación del estrato $\mathrm{C}$ respondió a una potencia media de 54 centímetros con un claro nivel de escombros, integrado por fragmentos de tejas, ladrillos, abundantes fragmentos de estuco pintado, un capitel de pilastra y una dovela con motivos florales esculpidos, que cubre al de restos que descansa sobre pavimentos duros en su totalidad.

Las estructuras descubiertas pertenecen a varias piezas de una vivienda construida hacia fines del siglo I de J. C.: sus citados pavimentos duros son de mosaico de tesela cúbica con decoración polícroma vegetal unos o totalmente lisos otros, en blanco a excepción de una banda lateral de ZZZ en negro, de mortero de cal otros y dos habitaciones más los tienen de plaquetas de mármol exagonales, cuadradas y rectangulares, rojas amarillas y blancas. Los zócalos de sus dependencias conservan pinturas murales de estilo geométrico, de imitación de mármoles, vegetal, animal o de candelabros. La parte central de la vivienda la ocupa una piscina, construcción sólida de mortero de cal y ladrillo picado, de 7 por 7 metros de superficie, con interior de siluetas recortadas en casetones y semicilindros entrantes y salientes, de 60 centímetros de profundidad, con paredes de 70 centímetros de grosor, bordeada de columnas con una equidistancia de 2 metros, de 80 centímetros de diámetro de base y 50 centímetros de diámetro de arranque del fuste, que tienen muescas laterales, indicio de que entre ellas debió existir una balaustrada o celosía, y que están revestidas de estuco pintado en rojo en su parte baja y debieron tener sus zonas medias pintadas con imitación de mármol y las altas con verde, 

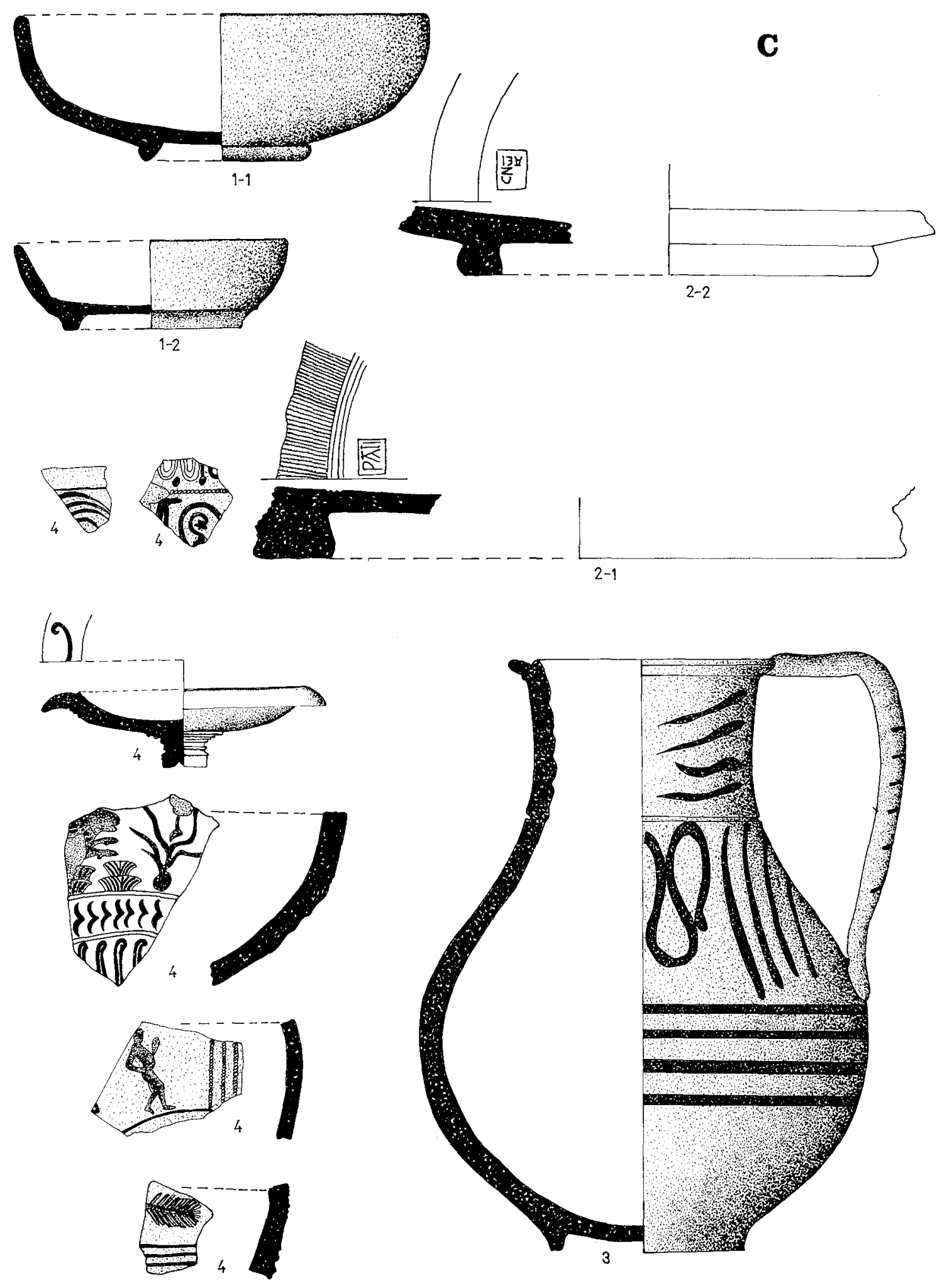

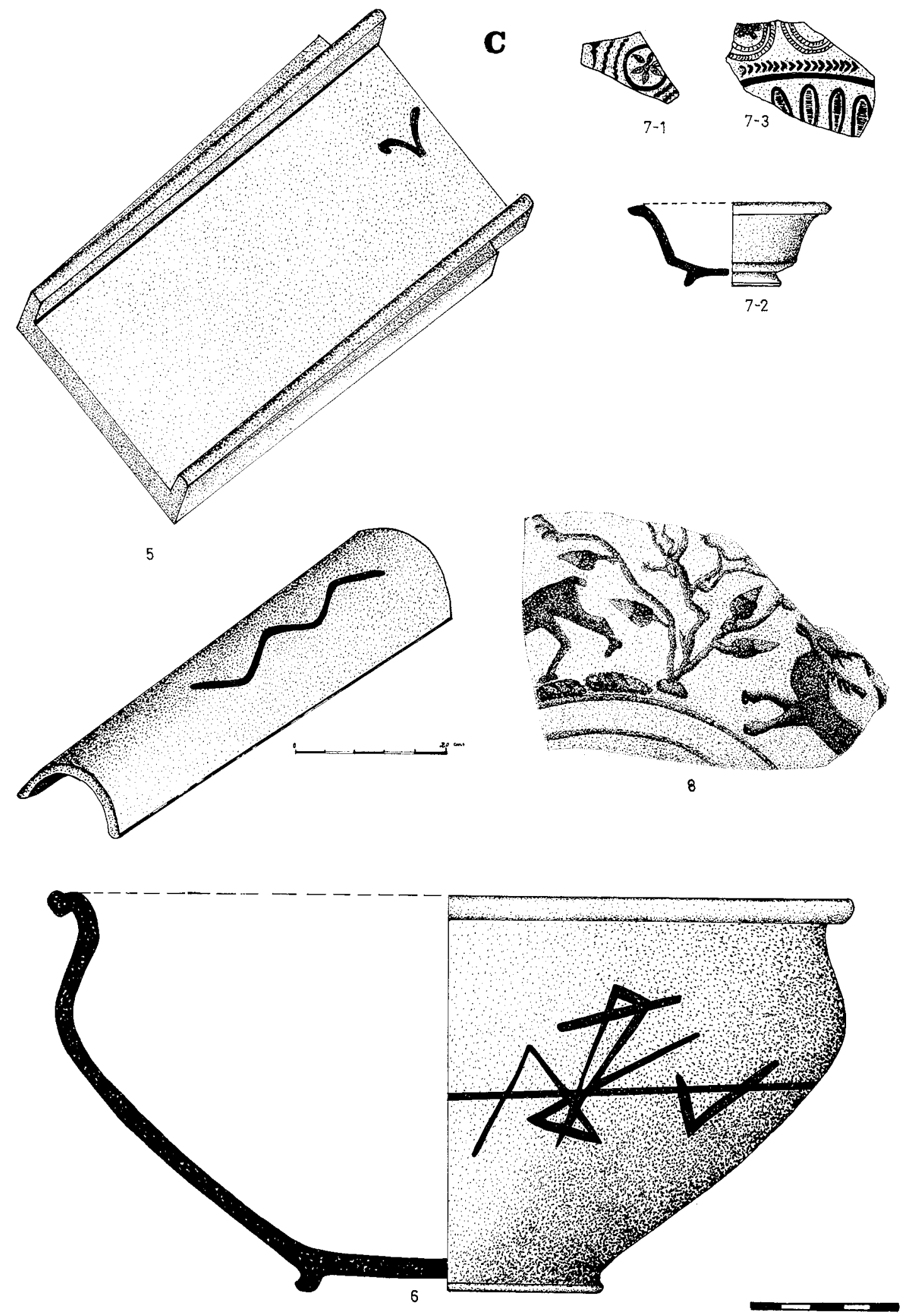
según se desprende de los muchos fragmentos de este estucado, de superficie curva, que han sido encontrados.

La referida piscina vierte aguas por dos conductos que separadamente conducen al alcantarillado de la vivienda; y completa el servicio de la casa el abastecimiento de agua por tubería de plomo. Ambas conducciones, de abastecimiento y de desagüe, emplazadas bajo los pavimentos, constituyen alteraciones de nivel pertenecientes a esta época.

El descubrimiento de estas estructuras ha implicado la imposibilidad metodológica de continuar la excavación en profundidad en los sondeos afectados por ellas en función de las construcciones romanas existentes. Por ello, en esta zona del sector, sacrificamos la investigación de los estratos inferiores y avanzamos la cuadrícula a este nivel y sólo en los sondeos que queden fuera de las citadas estructuras realizamos el estudio estratigráfico total del yacimiento en estos trabajos.

Los conjuntos materiales de este estrato están caracterizados por la presencia de olpes con decoración pintada de tradición ibérica, piezas de sigillata sudgálica, hispánica y clara, ánforas y estilos.

Ha sido consiguientemente significativo el hallazgo de un plato incompleto de pasta avellana y engobe exterior marrón claro, de 14 centímetros de diámetro de boca (fig. C-1.1); un fragmento de un pequeño vaso de pasta gris de $9 \mathrm{~cm}$. de diámetro de boca (fig. C-1.2); un fragmento de base de plato de sigillata aretina con marca (fig. C-2.1); un fragmento de sigilla sudgálica con marca (fig.C-2.2); varios fragmentos de un olpe con decoración pintada de tradición ibérica (fig. C-3); varios fragmentos de sigillata sudgálica (fig. C-4); varias tejas con marcas realizadas por digitación (fig. C-5); una vasija de barro avellana claro, de 26 centímetros de boca y 13,5 centímetros de altura, pintada en rojo con un posible anagrama como tema, que contenía los restos de un ave (fig. C-6); dos fragmentos de sigillata hispánica (fig. C-7. 1 y 3); una pequeña vasija incompleta de pasta gris (fig. C-7.2); y un fragmento de sigillata sudgálica (fig. C-8).

Levantados los pavimentos del estrato $C$, de un grosor medio de 11 centímetros, se alcanzó el estrato $\mathrm{D}$, correspondiente a la que hemos llamado época ibero-romana, comprendida entre mediados del siglo I a. C. y mediados del I de J. C., con una potencia media de 69 centímetros, cuyo nivel de pavimentos se encuentra consiguientemente a 2,07 metros de profundidad con respecto a la superficie del terreno.

La excavación de este estrato nos mostró parte de una vivienda en la que se aprecia cómo sus dependencias son origen de las de época romana que, con diferente técnica constructiva, utilizan sus muros como cimentación, con lo cual se evidencia que buena parte de la distribución de la casa mantiene los cánones de esta época en períodos, y consecuentemente en estratos, posteriores.

Este estrato $\mathrm{D}$ contiene pavimentos distintos en las diferentes habitaciones de la vivienda: un mosaico de tipo helenístico, otro de tipo signinum con una temática geométrica de rombos, otros constituidos por una solera de cantos rodados cubierta por una capa de cal muy compacta y de superficie pulida, otros de arcilla pisada sobre arenas, cantos y piedra pequeña, y otros de adobes.

Los zócalos o estucados de las paredes de algunas de sus dependencias son también de cal muy compácta y de superficie pulida, de calidad muy superior a los acabados de época romana.

Pero mención especial merece el citado pavimento helenístico, tanto por lo que representa como por el hecho de que se ha procedido a su levantamiento, consolidación y traslado al Museo Monográfico del yacimiento, y en el sondeo en que fue hallado se ha proseguido la excavación en profundidad, como en otros, hasta niveles asociables al Bronce Final.

El centro de este mosaico (2) lo constituye un rosetón, con pétalos estilizados de co-

(2) A. RAMOS. «Un mosaico helenístico en La Alcudia». A. P. L., XIV. Valencia, 1975. 
lor rojo y negro sobre fondo blanco. Se halla encuadrado por un marco de 100 milímetros de ancho formado por tres líneas de teselas blancas, rojas y negras, alternas, y a la derecha una banda de piezas como las anteriores en forma de ajedrezado. Esta banda se estableció para equilibrar el dibujo del mosaico, que en su lado norte ofrece en teselas color azul oscuro unas hojas de vid y unos pájaros sobre un fondo blanco; en el lado izquierdo hay una layenda: ACOS; y en el lado sur otra leyenda en tres líneas: ...L SAILACOS / ...EL SADINICOR / ...SCRAD... ¿Podría tratarse de nombres iberos transcritos en letras latinas?

Todo ello se halla enmarcado a su vez por otra banda de 260 milímetros de ancha, en la que discurre una línea de postas, adornada en los tres ángulos que se conservan por una hojas de vid y en el lado izquierdo por otra hoja a cuyos lados hay sendos pájaros.

Se completa este mosaico por otra gran banda en sus lados, de 900 milímetros, en la que se reproduce una muralla con cuatro torres en el lado este, de las cuales en una se señala la puerta; en el lado norte se conservan tres torres, y dos de ellas también se encuentran con sus puertas; y en el lado oeste sólo se aprecia el inicio o base de alguna de ellas.

Las piezas que integran este mosaico son de distinto tamaño y de materiales diversos. Las que forman las torres son todas de cerámica, de color ocre, y las puertas y fondo de piedras blancas; los pájaros y las hojas se han formado con teselas azules y negras; las letras de ACOS de ladrillo rojizo; las letras de SAILACOS y las otras leyendas, en cubos negros; las filas que separan las leyendas son de piezas de cerámica amarillo rojiza, puestas de canto; los pétalos del rosetón y los triángulos son de piezas blancas; el cuadro que encierra el rosetón es de cubos de cerámica amarilla y piedras blancas; y la fila intermedia del lado este, de piezas en rojo, blanco y negro; además hay otras zonas blancas formadas por fragmentos de pequeños cantos rodados.

En el nivel de restos de este estrato D, caracterizando su conjunto de materiales, han sido halladas cerámicas ibero-romanas pintadas con reticulados, estilizaciones vegetales, bandas de SSS como tema principal, hojas a tinta plana con esgrafiado de sus nervios, figuras antropomorfas siluetadas por esgrafiados, y peces, así como cerámicas campanienses B y C, cerámicas de barro gris de imitación campaniense, presigillata, sigillata aretina, lucernas de volutas y piezas monetales de la ceca local.

En este estrato ha sido especialmente significativa la presencia de una olla de pasta gris y paredes sumamente delgadas, de 8 centímetros de diámetro de boca (fig. D-1); una vasija con asas de cerámica pintada de tipo ibero-romano, decorada con temas de reticulados y estilizaciones vegetales (fig. D-2); un vaso troncocónico de pasta rojiza (fig. D-3.1); una lucerna de volutas de buena pasta y engobe marrón (fig. D-3.2); varios fragmentos de cerámica pintada de tipo ibero-romano (fig. D-4); un fragmento de cerámica pintada con una figura antropomorfa alada que sostiene en sus manos una arqueta y en la que, como uno de los rasgos distintivos del período, destacan las líneas esgrafiadas que siluetean los motivos de la decoración (fig. D-5); y un mortero de cocina incompleto (fig. D-6). Materiales que se asocian al hallazgo de un semis de Augusto de emisión local: A.- cabeza de Augusto rodeada de la leyenda AVGVSTVS DIVI F. R.- águila legionaria y vexilo entre C. C./IL. A., con dos enseñas legionarias a los lados. Arriba los nombres de los duumviros T. MANLIO. T. PETRONIO (variante 3). Abajo, II VIR; y a cinco monedas de Carthago Nova.

Levantados los pavimentos $\mathrm{D}$, de 12 centímetros de grosor medio, se excavó el estrato $\mathrm{E}$, perteneciente a la época ibero-púnica o ibérica II, de 38 centímetros de potencia, que cronológicamente situamos entre fines del siglo III y mediados del I a. C., con pavimentos de adobes dispuestos en posición vertical, de 19 por 14 por 9 centímetros, y cubiertos de una lechada de cal de 1 centímetro de espesor, y también en otras habitaciones, constituidos por enlosados de grandes piedras planas sobre un preparado o soporte de arcilla, o por pavimentos de cal de superficie muy fina sobre adobes o sobre piedras, con zócalos del mismo material. 

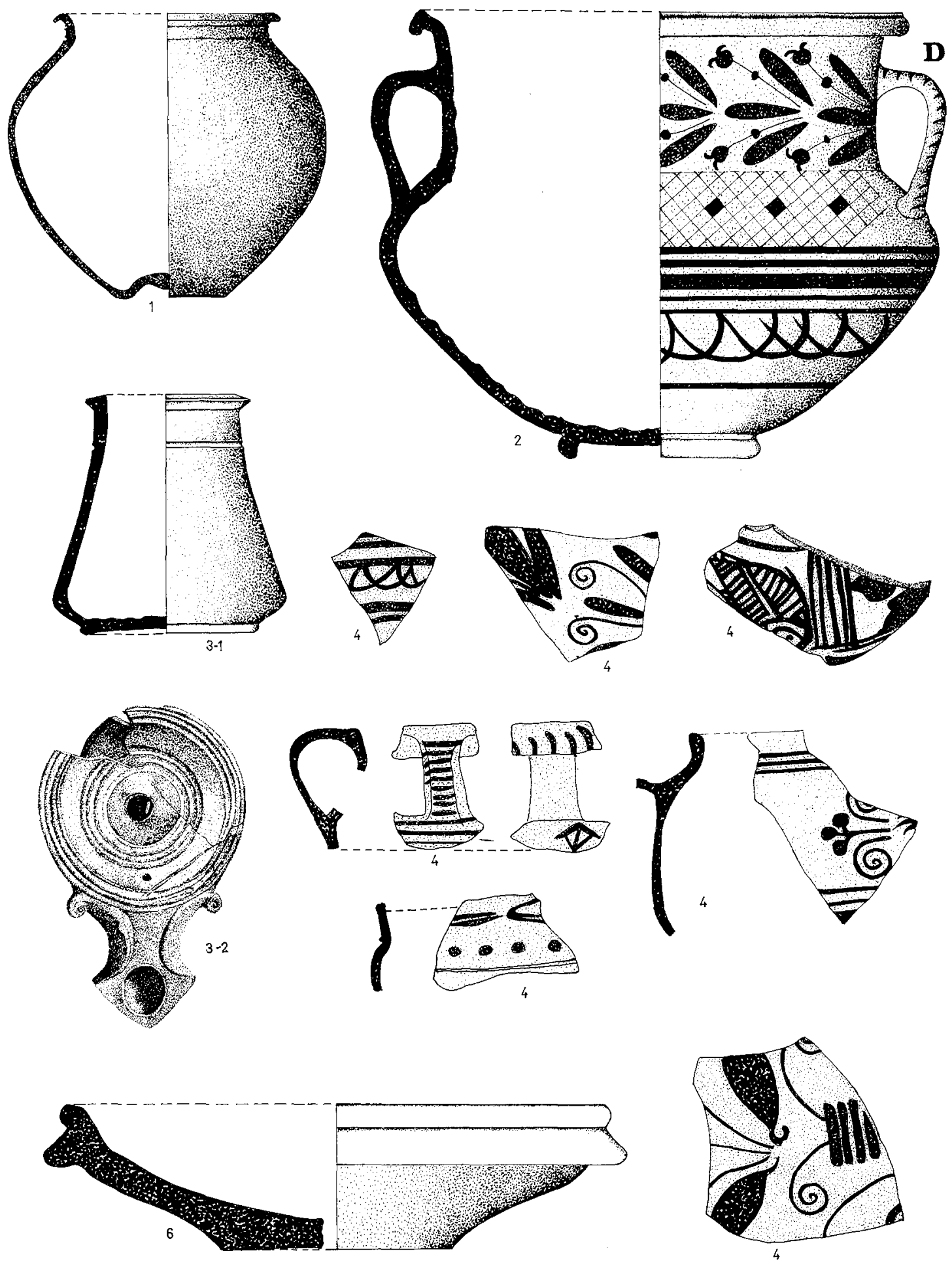


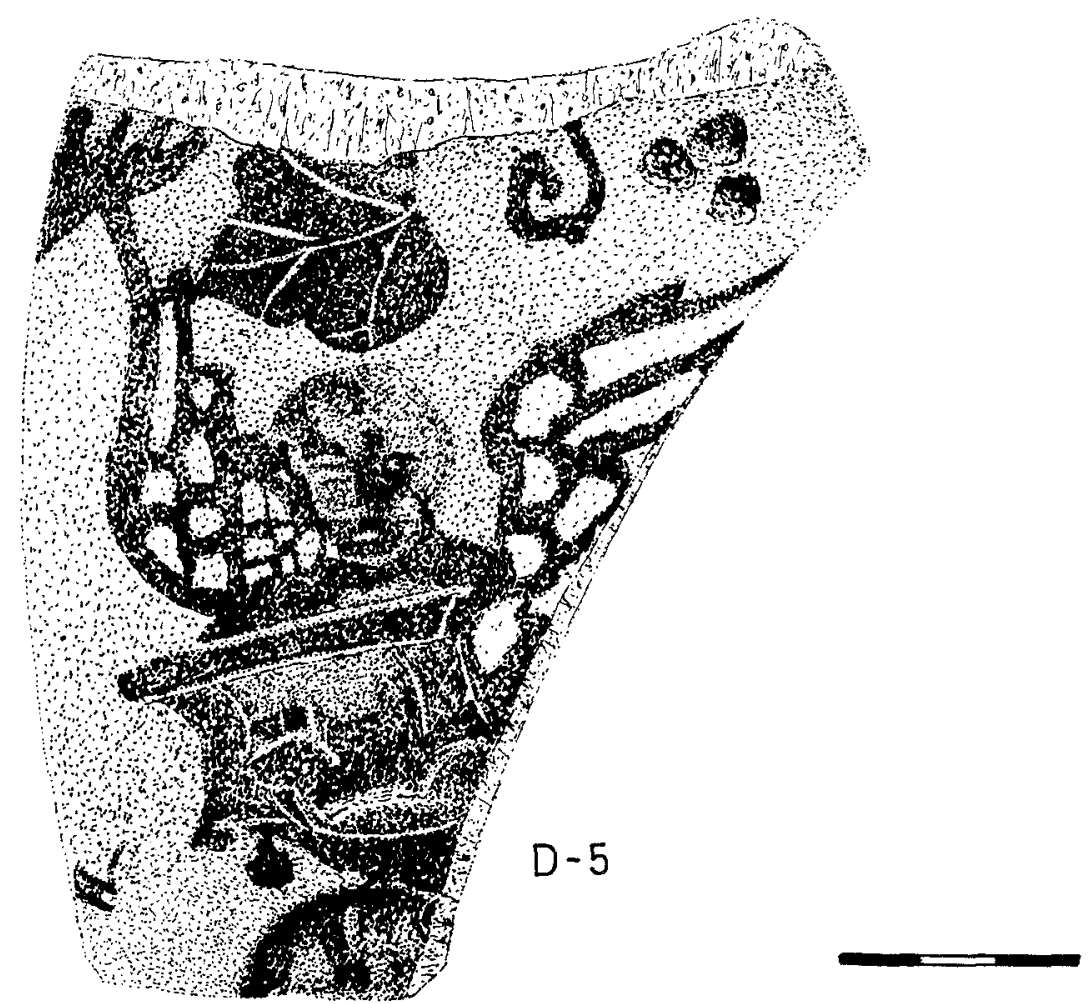

Las paredes de la dependencia de la vivienda son de piedra gruesa, diferenciada, que, al igual que en la época anterior, en una habitación ahora, sirvieron de cimentación a las estructuras que se le superponen en épocas ibero-romana, con piedra de tamaño menor, y romanas, que mantienen un tipo de piedra en las construcciones similar al del estrato $D$, pero combinado con bloques de sillería.

Los zócalos de estas habitaciones están estucados con pinturas polícromas y predominio de rojos y azules, de forma, colores y técnica diferente a los de estratos superiores. Sus colores son más suaves, sus temas distintos a los pertenecientes a épocas romanas aportados por este yacimiento, y la cal que las sustenta también ofrece una textura diferente.

Los conjuntos materiales de este estrato E están caracterizados por la presencia de fragmentos de cerámica pintada de tipo ibero-púnico o ibérico II, decorados con aves, rostros humanos, cuadrúpedos, peces y temas vegetales, así como por piezas de campaniense $\mathrm{B}$.

En este estrato $\mathrm{E}$ ha sido especialmente significativo el hallazgo de dos fragmentos de una vasija pintada con temas vegetales (fig. E-1); un fragmento de cerámica pintada decorado con un rostro humano bajo parte de un cuadrúpedo (fig. E-2.1); un fragmento cerámico pintado con la cabeza de un ciervo (fig. E-2.2); varios fragmentos de cerámica pintada típicos de este estrato (fig. E-3 y E-4); y un plato incompleto, de 26 centímetros, de cerámica pintada exterior e interiormente con bandas de líneas (fig. E-5).

Desmontados los pavimentos $\mathrm{E}$, de 18 centímetros de grosor medio, se procedió a excavar el estrato F, correspondiente a la época Ibérica I o Ibérica Antigua, de 49 centímetros de potencia, que cronológicamente ocupa desde el siglo $\mathrm{V}$ hasta los inicios del último cuarto del siglo III a. C.

Sus pavimentos son de enlosados de piedras planas o de arcilla rojiza endurecida de 6 a 8 centímetros de grosor sobre un soporte de arenas de 10 centímetros; y sus construcciones están constituidas por paredes de piedra, de mayores dimensiones que las de épo- 

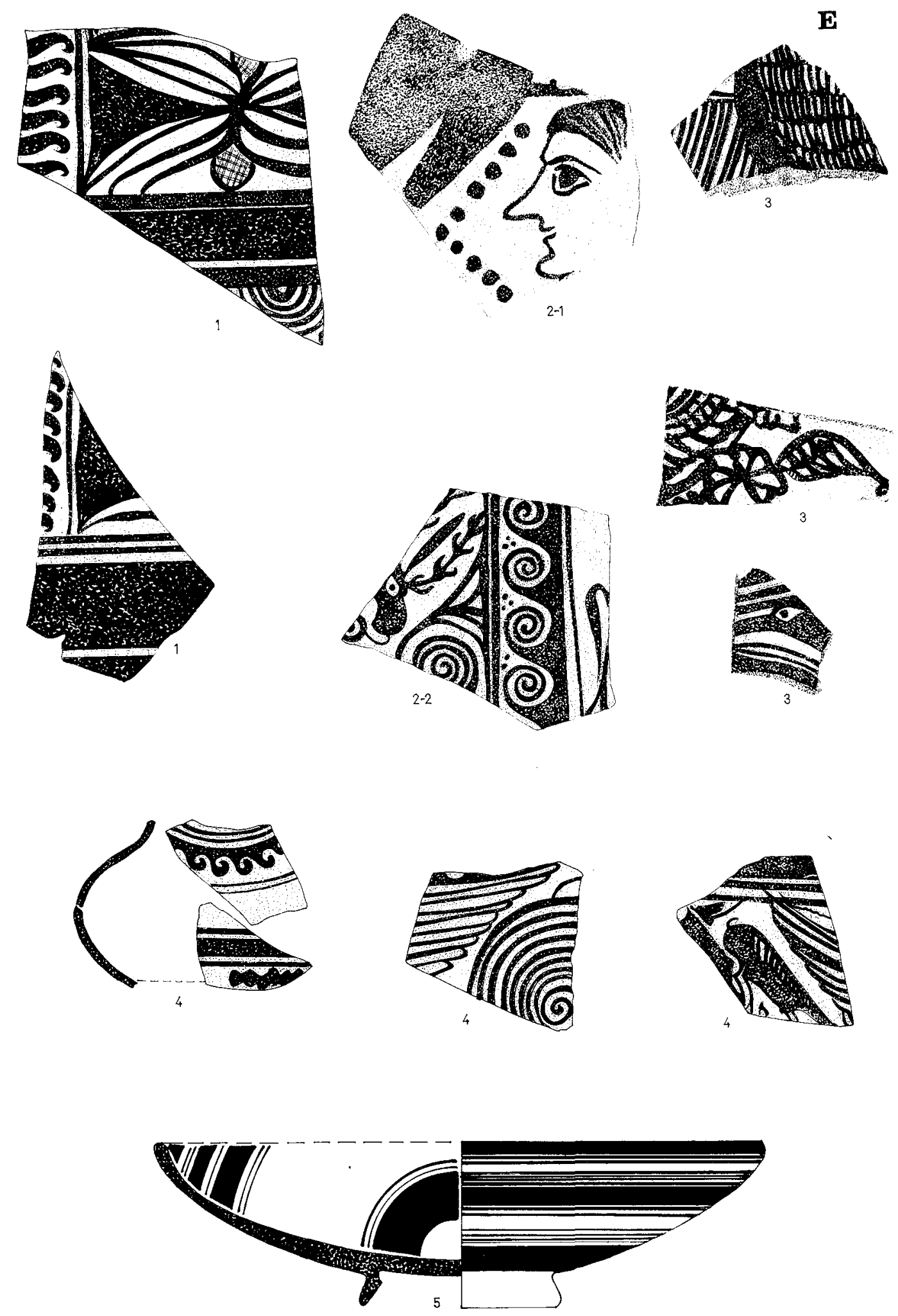

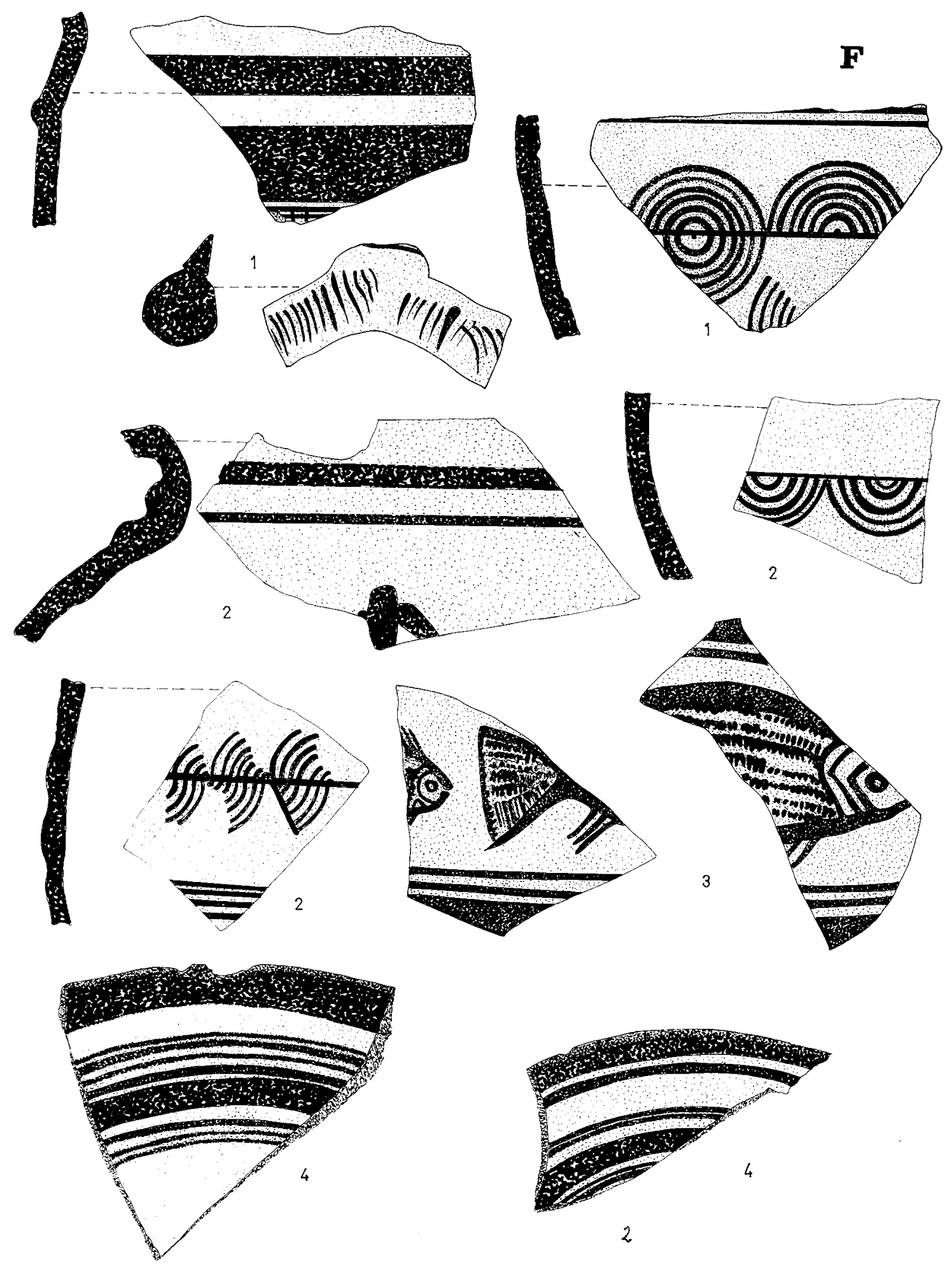

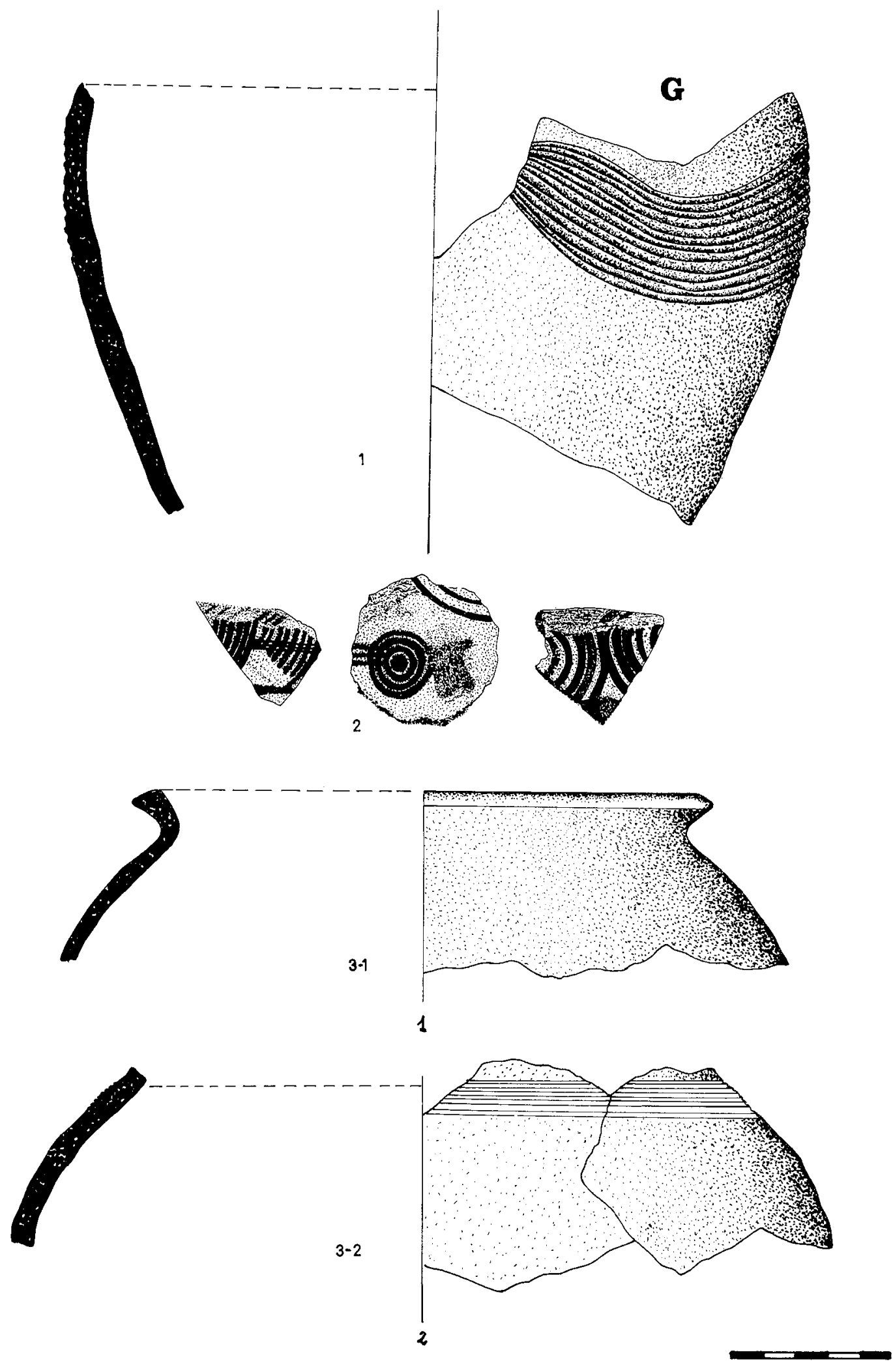
cas posteriores, que delimitan habitaciones rectangulares, y por un gran muro en su zona Este, posible defensa exterior de la ciudad dada su proximidad a la ladera del yacimiento, edificado con piedras de muy grandes dimensiones.

Sus materiales están caracterizados por la existencia de fragmentos de cerámica pintada con decoración geométrica típica de lo ibérico antiguo, con líneas, bandas y muy variadas combinaciones de círculos, semicírculos y segmentos de círculo concéntricos, así como por la representación de zoomorfos entre zonas de bandas; por fragmentos de platos de bordes rectos y de platos de bordes labiados decorados con líneas y bandas exterior e interiormente; y por fragmentos cerámicos de paredes gruesas y decoración pintada de tipo geométrico.

En el conjunto de materiales hallado en este estrato $\mathrm{F}$ ha sido especialmente significativa la presencia de varios fragmentos cerámicos pintados con decoración geométrica de círculos concéntricos, segmentos de círculos concéntricos, semicírculos concéntricos, bandas y líneas (fig. F-1 y F-2); fragmentos de un vaso pintado cuya decoración ofrece,
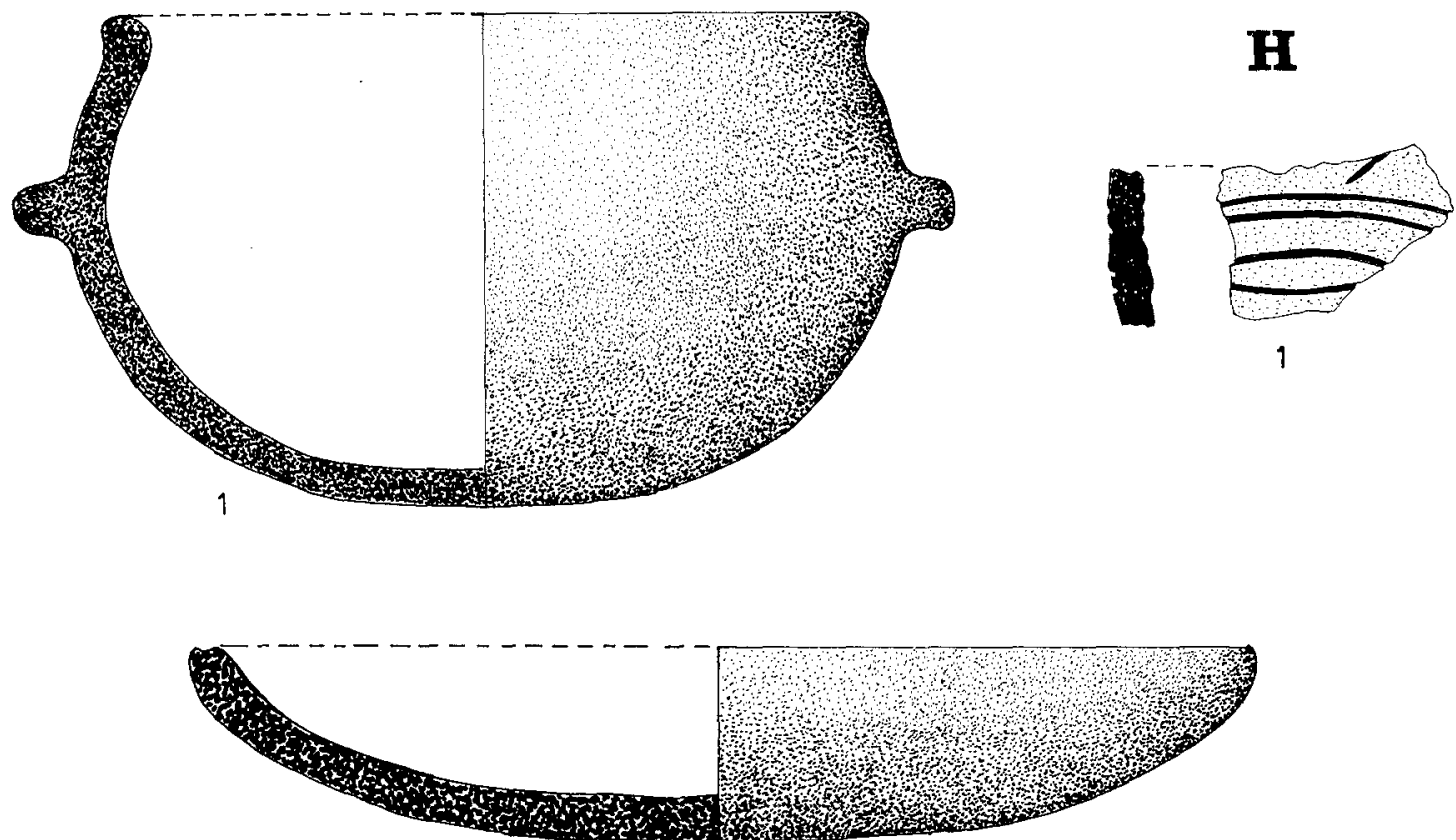

2

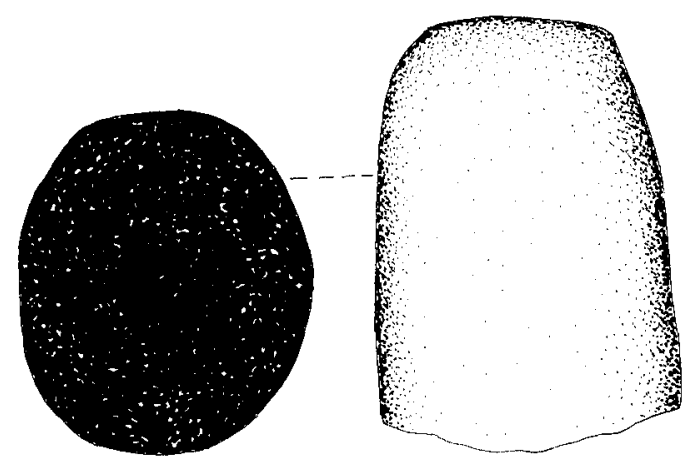

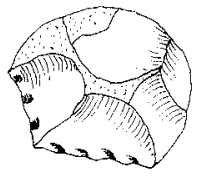

3

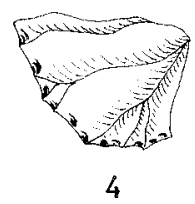

4 
entre bandas, unos peces (fig. F-3); un fragmento de plato de bordes rectos de cerámica pintada decorado con líneas y bandas exterior e interiormente (fig. F-4.1); y un fragmento de plato de borde labiado de cerámica pintada, decorado con líneas y bandas exterior e interiormente (fig. F-4.2).

Levantados los pavimentos $\mathrm{F}$, de 16 centímetros de grosor medio, entramos en el estrato $\mathrm{G}$, correspondiente al período que hemos llamado preibérico, que pudo desarrollarse durante los siglos VII y VI AC.

Este estrato, de 59 centímetros de potencia, contiene pavimentos de tierra pisada y de arcilla endurecida sobre arenas aunque, tal vez por las pequeñas dimensiones de las casillas excavadas, en función de haber respetado testigos de los distintos estratos, no hemos localizado las estructuras pertenecientes a tales pavimentos.

Los materiales de este estrato $G$ están caracterizados por la presencia de fragmentos cerámicos a torno, sin decoración y con engobes blancos, de posible importación griega; por fragmentos cerámicos con peinados en crudo revestidos de engobes; por fragmentos cerámicos de pasta muy dura y engobe blanco al exterior sobre el que se aplica la decoración pintada con óxido de hierro y manganeso de tipo geométrico; y por vasijas de cocina de superficies negras, torneadas, de pastas grises o rojas, con desengrasantes micáceos.

En su conjunto de materiales es significativa la presencia de varios fragmentos cerámicos revestidos de engobe blanco; unos fragmentos cerámicos con decoraciones de rameados o peinados en crudo revestidos de engobe amarillento muy consistente (fig. G-1); tres fragmentos de cerámica de pasta dura, de muy buena calidad, con engobe blanco al exterior sobre el que se realizaron decoraciones pintadas de tipo geométrico (fig. G-2); varios fragmentos de una olla de pasta gris con desengrasante micáceo (fig. G-3.1); y varios fragmentos de otra olla de pasta roja y superficies negras con una banda incisa a peine en su cuello (fig. G-3.2).

Desmontados estos pavimentos $\mathrm{G}$, de 24 centímetros de espesor medio, se penetró en la potencia del estrato $\mathrm{H}$, de 41 centímetros, asociable a etapas del Bronce Final, cuyos pavimentos, consecuentemente a 4,52 metros de profundidad, son de tierra pisada, endurecida y muy compacta.

Los materiales hallados responden a molinos de mano barquiformes, cuencos y escudillas de pasta gris con desengrasantes micáceos y modeladas a mano, hachas de piedra pulida y útiles de sílex.

En la excavación de este estrato $\mathrm{H}$ ha sido muy interesante la presencia de un cuenco incompleto modelado a mano, con apéndices laterales, de pasta gris con desengrasantes micáceos y ennegrecida al exterior (fig. H-1.1); un fragmento de una escudilla modelada a mano, de pasta gris con desengrasante micáceos y ennegrecida al exterior (fig. H-1.2); un fragmento cerámico modelado a mano, de pasta gris-amarillenta, con decoración exterior arañada y superficies lavadas (fig. H-2.1); la mitad perteneciente al talón de un hacha de piedra pulida (fig. H-2.2); un nódulo de sílex (fig. H-2.3); y un raspador frontal de sílex (fig. H-2.4).

La śecuencia estratigráfica observada en la excavación de este sector 5-F y los conjuntos de materiales hallados integrantes de cada uno de los períodos, ratifican plenamente todos los estudios ya realizados en el yacimiento de La Alcudia de Elche. 